

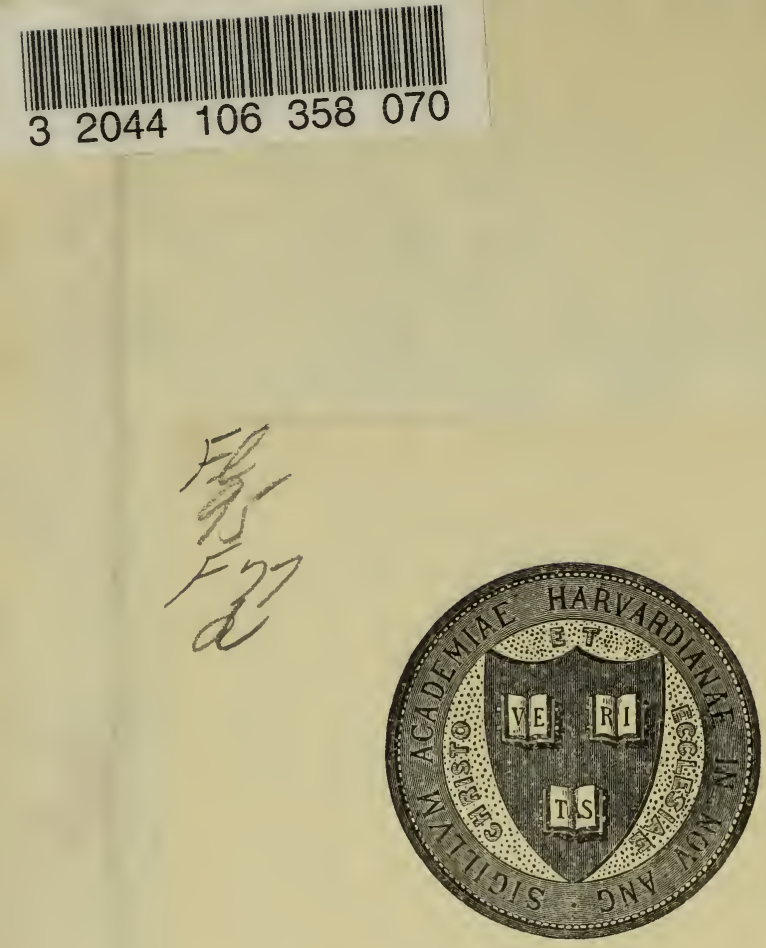

HARVARD UNIVERSITY

\section{I B R A R Y}

OF THE

\section{GRAY HERBARIUM}

Received 

;!

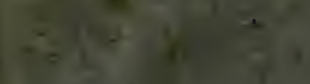
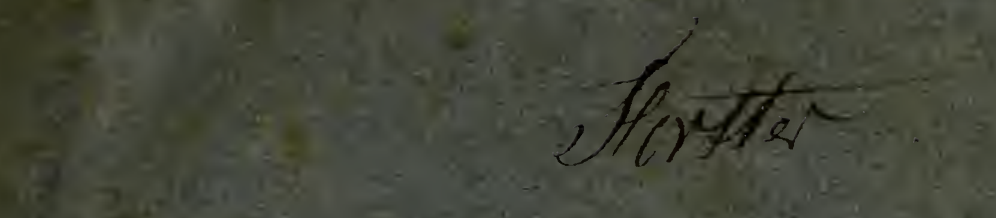

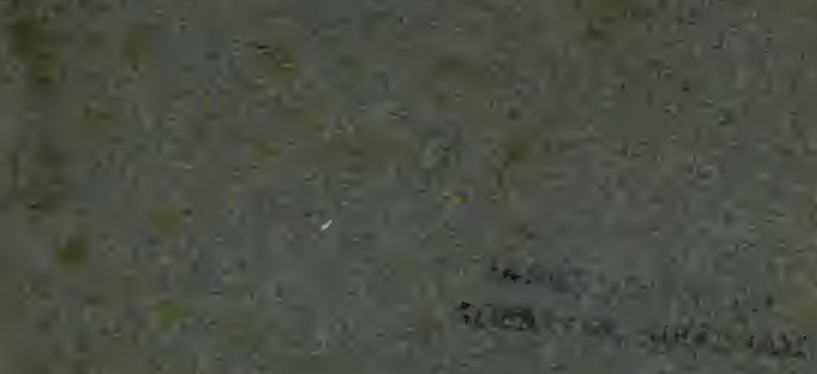

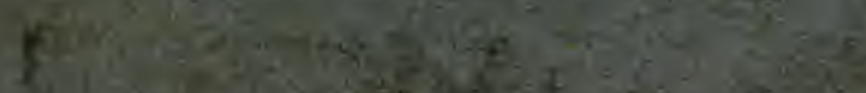

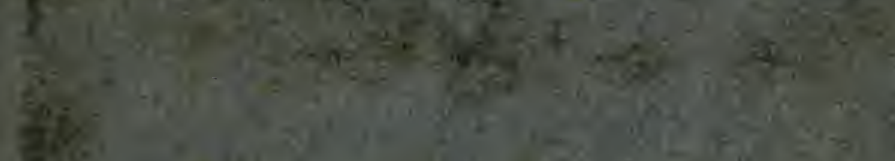

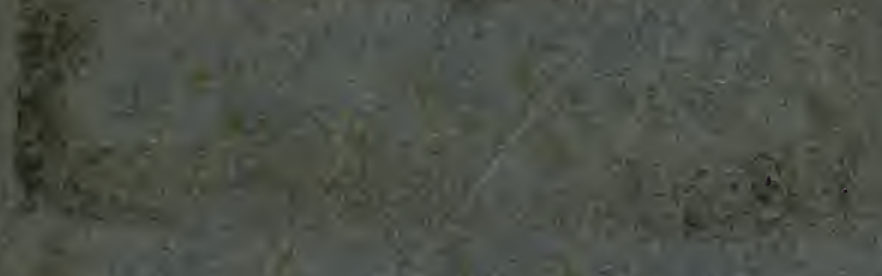

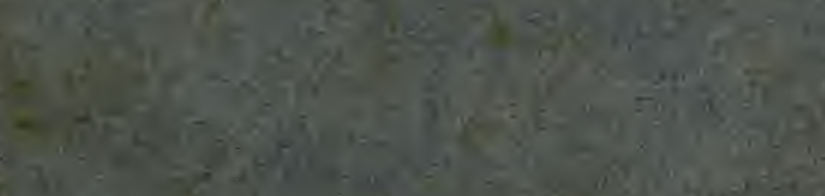

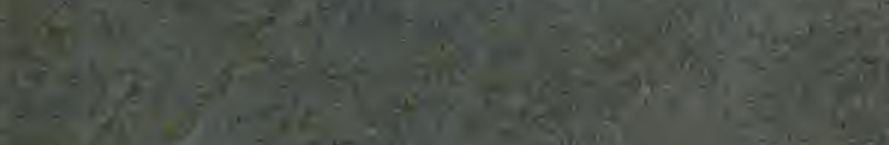

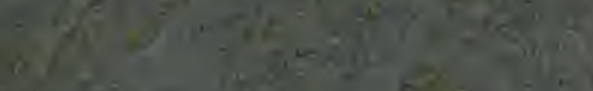

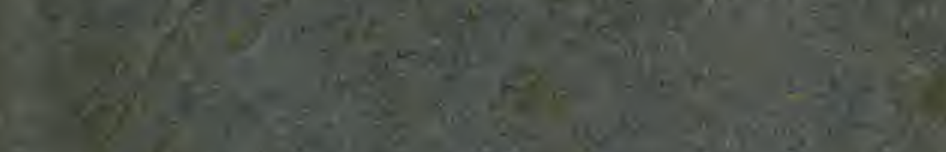

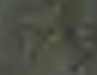
$-=$

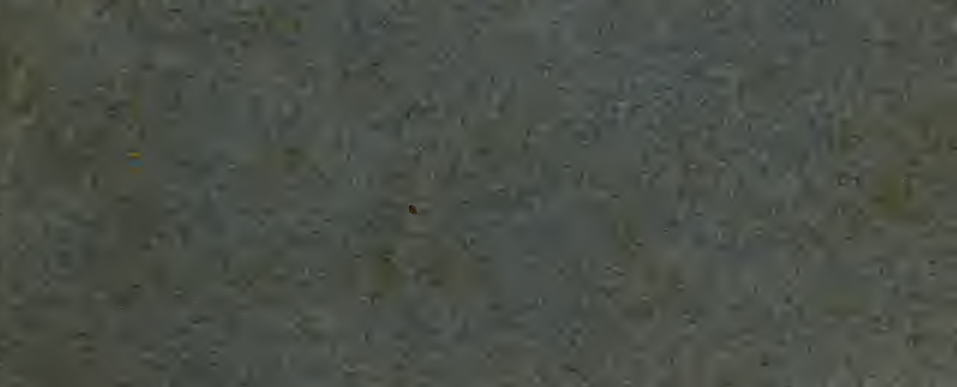




\section{A 11884}

CRAY HERSARHMA GARVARD UNIVERSTI

HARVARD UNIVERSITY HERBARIUM.

THE GIFT OF

Stac Clay. 


\title{
GEORGIII FORSTER,
}

\author{
MEDIC. DOCT.
}

SERENISS. POZONIAE REGI A CONSILIIS INTIMIS, ETC.

DE

\section{PLANTIS ESCVLENTIS}

\section{INSVLARVM OCEANI AVSTRALIS}

\section{COMMENTATIO BOTANICA.}

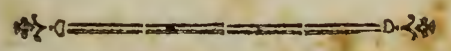

Sed primum politum fit, nosmet ipfos commandiatos efle nobis, primamque ex natura hanc habere apperitionem, ut confervemus nosmet ipfos.

CIC. de finib. boib, et anal. L. IV.

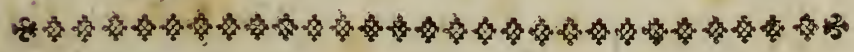

$$
\text { BEROLINI, }
$$

APVD HAVDE Et SPENER, M D C C I XXXVI. 


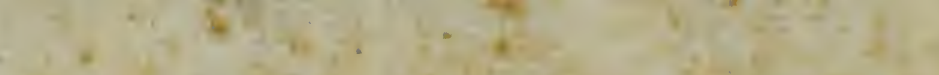

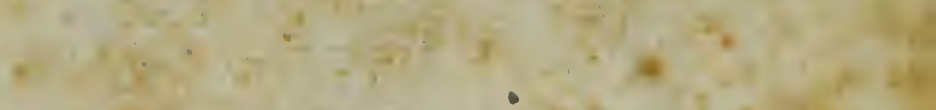

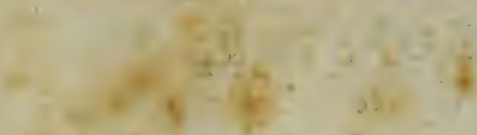

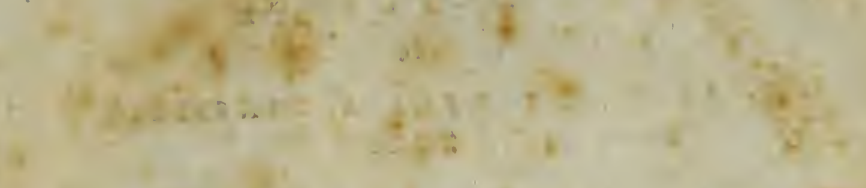

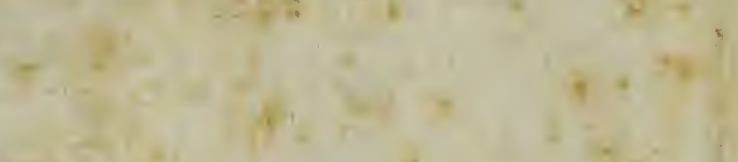

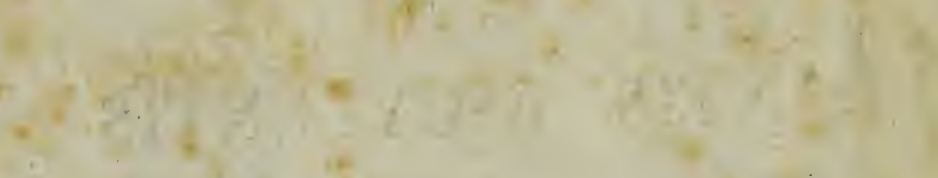

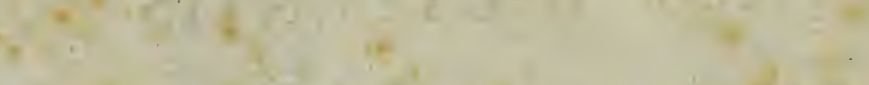

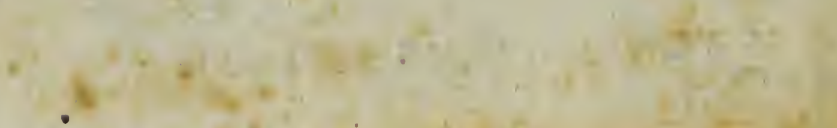

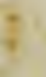

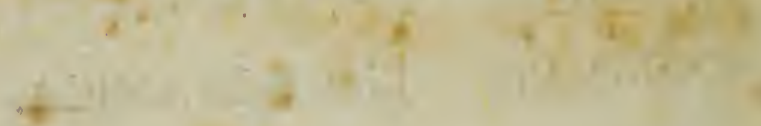
$\sqrt{2}$ 19

$=1$

$7=1$

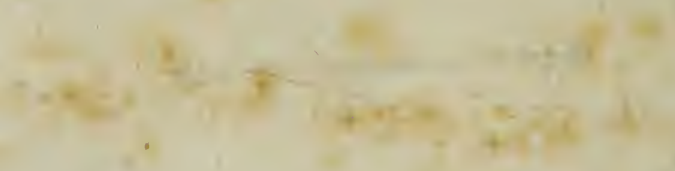

$+$
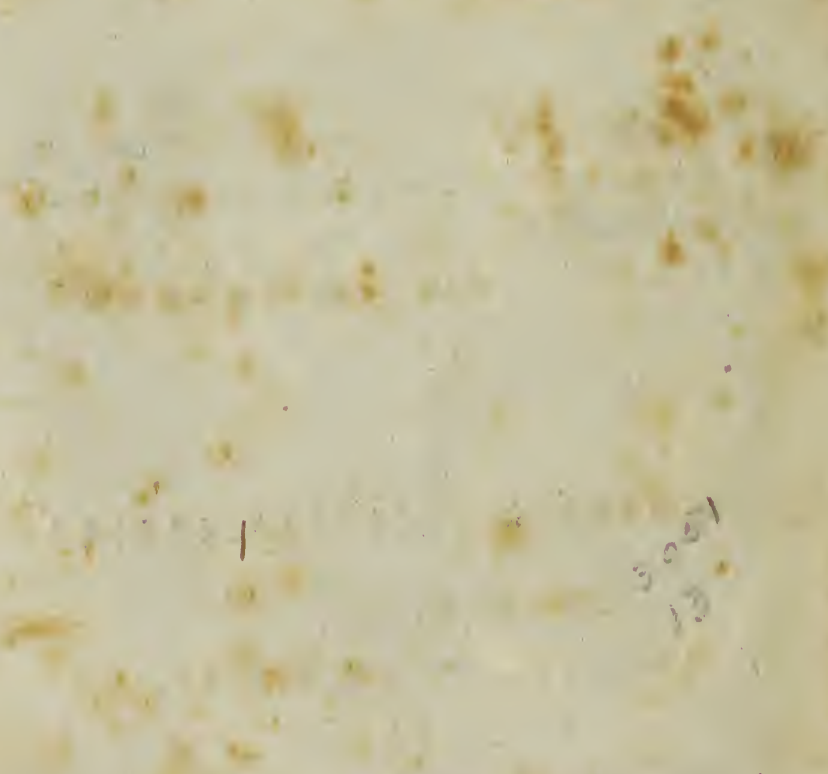

b.

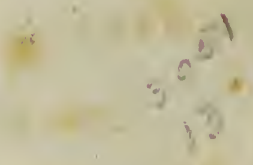

$+$

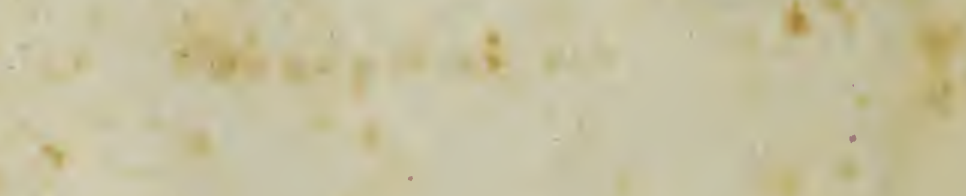

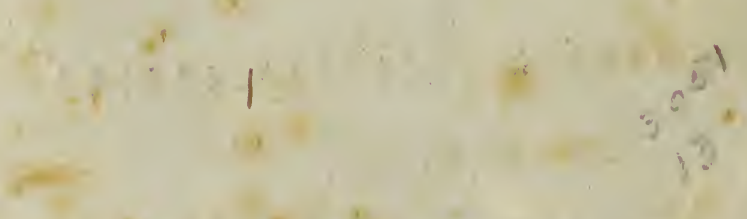
(1) 


\title{
V I R O
}

\section{ILLVSTRI ET GENEROSO}

\section{IOANNI ANDREAE M V R R A Y,}

ERVITI ORDINIS DE WASA, CONSILIARIO REGIAE AVLAE, PROFESSORI MEDICINAE ET BOTANICES IN ACADEMIA REGIA GOETTINGENSI, REL.

$$
\text { BOTANICO }
$$

NOSTRI AEVI PRIMARIO

H V N C

DELECTVM FLORVLAE AVSTRALIS

\author{
PIENTISSIME CONSECRAT
}

GEORGIVS *FORSTER。 


\section{1. $\%$ \& $\%$}

2.

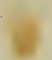

w

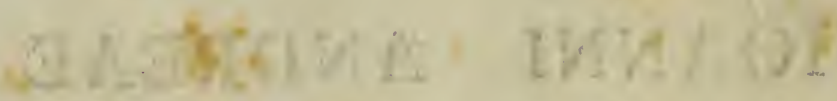

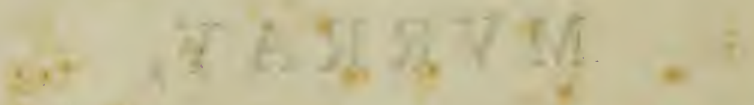

, L E

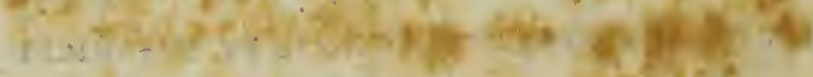

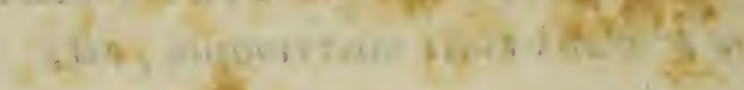

$+$

is.

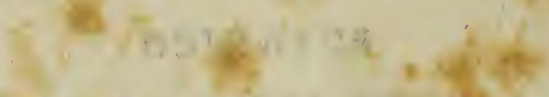

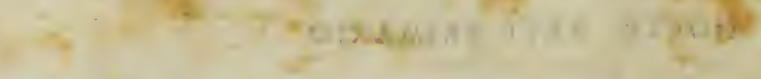
$+$
$-2$

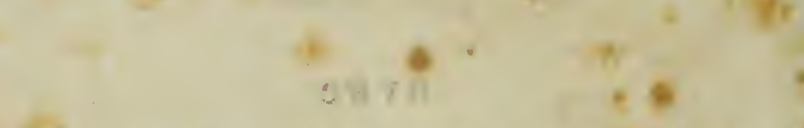
N

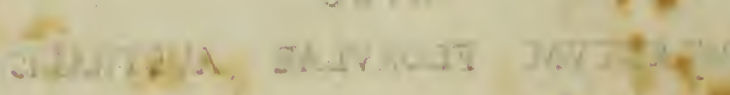

Ir

.

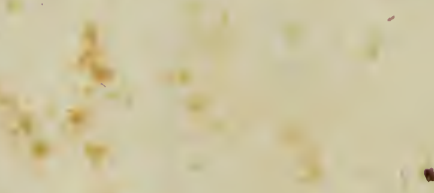
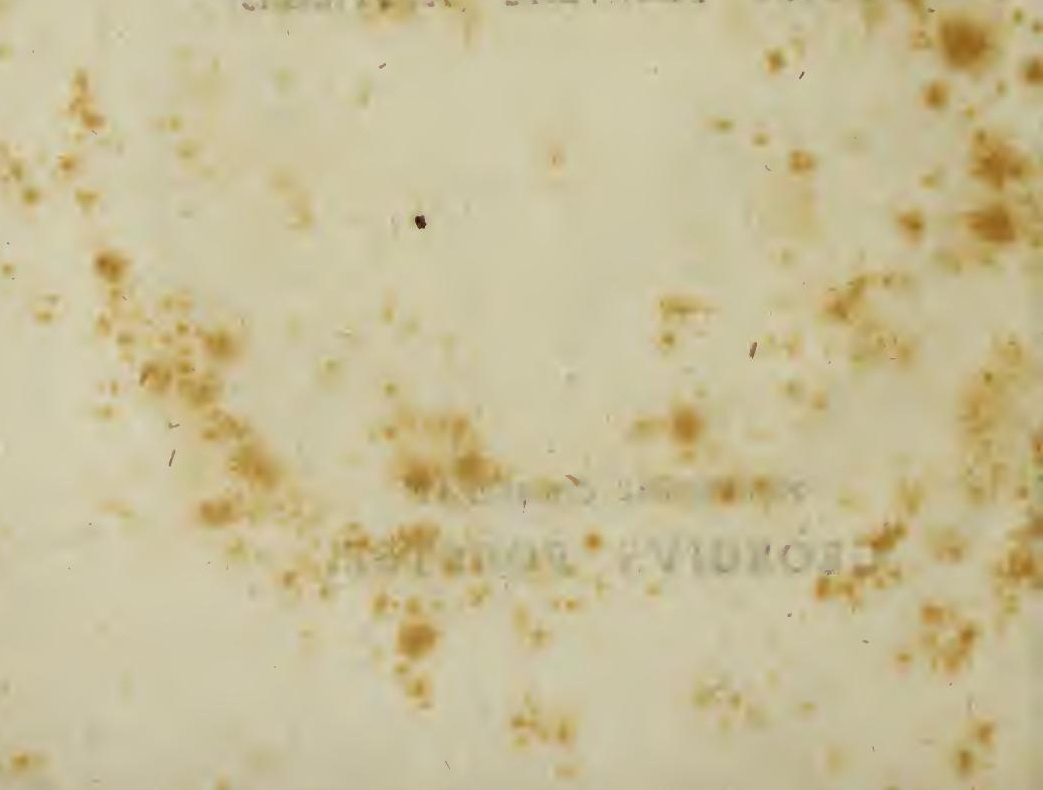

(4) -2 


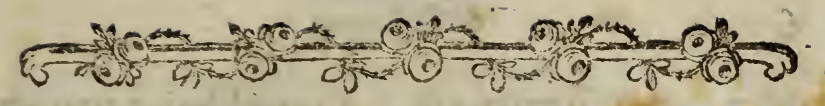

PRAEFATIO.

A

fiam inter orientalem et Americam zephyrinam late extenditur Oceanus auftralis, omnium vaftiffimus, nullis extra zonam torridam, praeter unicam fere novam Zeelandiam terris interceptus; intra tropicos autem plurimis infulis, veluti punctis confperfus, quarum aliae in congeries aliquot collectae, aliae majori fpatio disjunctae jacent. Verfus occidentem inde a decimo quem vocant latitudinis auftralis gradu usque ad quadragefimum quartum, idem oceanus novam Hollandiam, Europa maiorem, alluit.

Incolae harum terrarum alii candidiores funt, alii nigricantes. Priores numero reliquis praeftant, uno eodemque fermone utuntur, morumque fimilitudine, quantum pro climatum diverfitate licuit, inter fe conveniunt. Ex Indiae regionibus orientalibus per archipelagum moluccanum atque philippinas infulas in oceanum auftralem eosdem migraffe, propter analogiam linguae eorum vernaculae cum ma- 
laica, certiffimum eft. Oceani huius partem borealem tropico tamen inclufam, tres infularum congeries occupant, Latronum quae et Marianae dicuntur, Carolinae, et noviffimo Cookii itinere dete $t a e$ Sandvigiae. In ea parte quae trans aequatorem ad auftrum fita eft, totidem archipelagis, Amicorum fcilicet, Societatis et Marchionis Mendozae, fedem figerunt; quibus adnumerari debent infulae illae, hinc atque illinc in oceano difperfae, cuius fuperficiem vix fuperant, ftupendis lithophytorum habitaculis inaedificatae, nobis demerfae (Low Iflands) dicendae. Eiusdem ftirpis porro ramentum extra tropicum auftralem, verfus americae littora in pafchali infula reperitur (Oftereiland), aliud deinceps ex oppofito novae hollandiae nova Zeelandia eft, inde a tricefimo quinto ad quadragefimum feptimum latitudinis gradum protenfa.

Nigrae gentis longe alia eft ratio; nam in Indiae archipelagis orientalibus, et praefertim in montuofis fylvaticisque infularum latibulis agreftium hominum familiae reperiuntur, quae forte cum hisce auftralioribus nigritis ex eadem ftirpe prognatae funt. Eiusdem gentis praecipua fedes eft illa infularum congeries, quae. aequatori et moluccanis infulis proxima, $\mathrm{Pa}$ puae five novae Guineae, Britanniae, Hiberniaeque nominibus in tabulis geographicis defignari folet. Inde per infulas Charlottae, novasque Hebrides ad novam Caledoniam usque haecce nigritarum proles videtur penetraffe, breviffimo certe, fi cum eo conferatur, quo candidiores illi homines novam Zeelandiam et extre- 
mam pafchatis infulam petierunt, itinere, et a primis fedibus minus remoto. Nigri huius populi forte foboles, etiam novam Hollandiam occupavit, licet hoc certo affirmare non aufim; quod fi vaftiffimae iftius regionis incolae re vera originem trahunt a Papuanis, dandum id quoque eft, eos a climate et carnium efu aliquanto immutatos fuiffe. Vérum enim vero nigrorum hominum in hisce terris in primis ea eft fingularitas, ut fere in qualibet infula, licet proxima vicinitate cum reliquis coniuncta fit, proprio diverfifimoque fermone utantur; totque paene fint idiomata, quot funt infulae $a b$ iisdem habitatae. Quo quidem argumento nullum exquifitius immanitatem maiorum, a quibus ortum trahunt comprobare videtur; et enim quis eft, qui indomitam feritatem fimul et infcitiam climatis ubertate altam in eo potiffimum non agnoscat, quod praeter victus parandi rationem, nihil a parentibus didicerint, defertisque laribus etiam patrii fermonis obliti fint?

Singularem hanc diverfitatem inter $\mathrm{Au}-$ ftrafiae vel Polynefiae populos, cum iam neque aëris, qui omnibus idem propemodum eft, neque alimentorum, quibus omnes fere iisdem vescuntur, diverfae qualitati tribuenda fit, originem ducere a primitiva autochthonum varietate arbitror. Indelebilis enim et tanquam inufta fpecies, diverfis hominum familiis inhaeret, plurimis notis charąterifticis infignis, quae et climati omnimodo refiftit, et ciborum commutatione non frangitur, nec non perpetua fucceffione, nifi contaminatae fuerint generati- 
ones aliqua mixtela, a parentibus ad uttimam prolem integra meraciffimaque defcendit. CuI affertioni ne teftimonia defint ex aliis regionibus deprompta, verbo faltem tetigife fufficiet aethiopum five nigritarum e propris fedibus africanis in peregrina climata translatorum generationes, atro colore, crifpa in capite lana, porreßtis maxillis, nafo fimo, labis tumidis, ceterisque indiciis ab optimo Soemmerringio, fummo incifore, mihi $\left(^{*}\right)$ nuper enumeracis, atavis femper fimillimas. Attamen de origine harum in genere humano varietatum aliquid certi vel ea ratione conftitui nequit, quod in univerfum hiftorica traditione antiquiores lint, et Iudaeorum oracula, quibus Europaci e confuetudine piè affentiuntur, de isdem fileant. Cum autem ludaeos femel in fcenam evocaverim, eosdem non dimittendos judico, priusquam eorum exemplo varietatum humanarum perfiftentiam firmaverim. Plurima enim fecula non fuffecerunt ad abluendam iftam notam vultui horum hominum adeo profunde infculptam, qua vel a primo intuitu afiaticam eorundem originem, meridie clarius perípectam habemus.

Quod ad climatis temperiem attinet, illud nimirum in novae Hollandiae defertis fiticulofis, inter calidifirma jure seferri poteft, neque huius parti boreali, aequatori vicinae, ipfam africam aequinotialem aeftuofiorem exiftinarem. Infulas vero, per oceanúm difperfas, ven-

(*) Ueher die körperliche Verfehiedenhcit des Negers vom Europäer. Frankf, u. Mainz 8. 7785. 
ventorumque intra tropicos perennium halitu perflatas. faluberrima et amoeniffima coeli temperie gaudere, navigatores quotquot ad easdem appulerunt omnes une ore promnciant. Novae Zeelandiae, licet frequentibus procellis exagitetur alpesque fuas perenninive obrutas in altum adtollat, nihilo tamen fecius leniores funt brumae, cum in eius parte extrema ad quadragefimum quintum usque gradum latitudinis in auftrum converfa, fub ipfo fine autumni herbas et frutices florentes legifiem.

Qui Carolinas, Marianas, Sandvigias, Mendocinas, Societatis et Amicorum infulas tenent, primae gentis homines, elegantioris funt formae, colorisque puriffimi caltanei absque ullo nigredinis inquinamento. Statura corum mediocris eft, ad proceritatem accedens; capilli longi, denfi. cincinnati, nigri; barba maribus crebra, prolixa; oculi ampli, iride nigrofusca; nafus latiusculus, nec fimus; labia crasfciuscula, dentes pulcherrimi. Magnates colore faepius lucidiore dignofcuntur, corpore proceriore, robufto, obefo, abdomine ampliffimo. Sed exceptionem habent infulae aquae penuria laborantes E- uwa, Tonga, Namoka, Pafchatos, quarum incolae, etiam natu principes, plerique gracilioris funt formae.

Ingenium horum hominum mite, morum comitate quadam et manfuetudine coniunctum, at in bellis in faevam ferocitatem degenerat. Respublica omnibus feudalis eft, regis moderamini fubiecta, cuius in amicorum infulis nullo limite circumfcriptam poteftatem, in focietatis 
archipelago potentiores vafalli coërcent. Vulgus hominum clientibus conftat, et mancipiis glebae adfcriptis, regiturque polytheismi fuperfitione, quae in $\mathbf{S a n d v i g i i s ~ p r a e f e r t i m ~ i n - ~}$ fulis profundiores videtur radices egiffe, verum etiam apud Taheitenfes interdum humanas victimas erogat. lis in univerfum monogamiae confuetudo, vix a nobilibus, militibusve fpreta. Veftimentorum genus laxum, leve, climati accomodatum; balneum frigidum bis de die, matutinum et vefpertinum; unguentorum ufus inprimis inter magnates frequens; moderata in laboribus domefticis exercitatio; nocturni aëris intemperies fedulo evitatur; mollis denique libido, rifus, joci, fabulae, cantilenae et faltationes ad tuendam fanitatem vitamque ad ultimum terminum protrahendam conferre videntur.

Vidus ratio, apud hancce gentem quam fit congrua valetudini robuftae et integrae, videndum eft. . Artocarpi fruetus farinaceo-pulpofi ab Otaheitenfibus, infularumque Societatis, Mendocinarum, Sandvigiarum, Carolinarum et Latronum indigenis loco panis adhibentur, primis octo menfibus in anno maturefcentes, fed tamen ante maturitatem perfectam in cibum cedunt. Hi decorticati, foliisque obvoluti, in fornace fubterranea per horulam affati, comeduntur. Reliquis quatuor menfibus mufae inprimis fru\&us, radicesque ari, diofcoreae, dracontii, taccae, convolvuli, hominibus cibum fuppeditant; quem ter fingulis diebus capiunt, plerumque refrigeratum, interdum tepidum, nunquam vero ferventem. Artocarpi fructum, quem 
quem blando alimentorum vegetabilium generi adnumerari non dubitem, variis modis praeparatum, five acidulatum fermentatione, five cum oleo et nucleis cocos nuciferae commixtum frixumque mignates quidem in deliciis habent, fed eidem lautiores quoque epulas adjiciunt; pisces enim fapidiffimos, pullos gallinaceos, porcinas, caninasque carnes in conviviis magna quantitate ingurgitant. Horaeis porro fruEtibus Spondiae, Mufae, Eugeniae crudis fubinde vefcuntur.

Sale marino in littore radiorum folarium ope concreto in Sandvigiis infulis ad cibos faliendos utuntur. Societatis infulae fale concreto carent quidem, fed eius loco aqua oceanica pro embammate adhibetur; in pafchatis demum infula, nimis arida et aqua pura omnino deftituta, non raro falfam pro potu ordinario hauriunt. In Marchionis, Societatis, Sandvigiisque infulis fcaturigines aquae frigidulae, puriffimae, leviffimae abundant, communique ufui inferviunt. Qui delicatius vivunt, lympham nucibus cocos inclufam forbillant. Sacerdotum autem turba et magnates extractum radicis piperis methyftici potant, quod non folum toxicis viribus eosdem inebriat, fomnoque gravi opprimit, fed etiam corpus lente emaciar, et leprae obnoxium reddit. Abominandum hocce temetum in amicorum infulis praefertim ufitatifimum eft Ibidem plurium caufarum jun ta operatione plane efficitur, ut homines, ex eadem ftirpe cum Taheitenfibus et Sandvigianis prognati in univerfum tamen minus robufti evadant, eorumque proceres non adeo pin- 
pinguescant, fanguinis autem acrimonia maiore laborare videantur; unde vel elephantiafin, vel totius corporis fqualidiffimam purulentamque exulcerationem non raro generatam fuiffe novimus. Quum enim huius archipelagi auftraliores infulae, fontibus et rivulis aquae purioris penitus careant, incolis fuis non folum potum falubrem, fed etiam balnea in climate aefuofo maxime falutaria denegant. Deinde, quod forte maximi momenti eft, blandiffimi ar. tocarpi fructus ibidem rarius occurrunt, atque radices jam commemoratae ari, dioscoreae taccae, huius alimenti faluberrimi vices agunt, quae licet coftura vel toftione a volatili et fere deleteria caufticitate liberentur, tamen adftringentium et acrium indolem non ita plane exuunt, ut fufpicionem movere omnino non valerent, apud homines iisdem perpetuo altos tandem maffam fanguinis et humorum exacerbari, nimiaque acredine accendi poffe. E contra vero blandiori diacta, horaeisque fruetibus aquofis ufi taheitenfes, aquae potatores, quorum corpora crebris ablutionibus humeEtantur et emolliuntur, non poffunt non obefiores reddi, cum revera fucci corporis humani tot diluentium juncta adione nimis debilitarentur, nifi tranfpiratio in regionibus calidioribus abundantior, phlegma fuperfluum tolleret.

Sunt qui climatis influxum in res humanas pertinaciter negant; ii Novam Zeelandiam vellem adeant, cuius regionis incolae cum Taheitenfibus et indigenis archipelagi Amicorum fermone conveniunt, cum quibus etiam fabulae reli- 


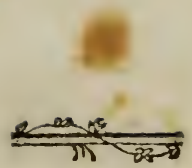

religiofae, et traditiones, nec non ipfe vultus et color communem iisdem originem fuife teftantur. At profecto maximam inter hasce gentes ortam a climatis neceffitate morum diverfitatem mirarentur. Primi enim novae Zeelandiae coloni, qui ad huius regionis oras boreales appulerunt, faccharatum licet convolvulum chry forrhizum, radicesque ari et diofcoreae fecum attuliffent, piscaturae tamen, quae facilem commodamque viftus rationem iisdem pollicebatur, fefe addixerunt; horticulturam, prout operofior erat, fenfim verfus auftraliorem extremitatem terrarum errabundi prorfus deferuerunt. Quare fingulis familiis infulam pervagantibus et $a b$ invicem fegregatis, cum jam nullo focietatis vinculo amplius compefcerentur, ad libidinofam ferocitatem patebat reditus. Incertus enim pifcaturae proventus eas frequenter loco migrare coëgit, ut viktui profpicerent; hinc inter diverfas familias, quotiescunque fame perductae in idem littus pifcofum efcendiffent, de Littorum dominio acerrime dimicatum eft. Apud victos inde pariter ac victores irata fames aluit inimicitiam, animosque fibi invicem infenfiores reddidit. Eo ufque tandem vindictae cupiditas apud irritabile illud et iracundum genus hominum invaluit, ut etiam in occifos hoftes dentibus faevire affueverint. Cum igitur bellicam virtutem et fortitudinem maximi faciant, neque cuiquam honorem habeant, nifi corporis viribus plurimum polleat, hinc iniquam et vere tyrannicam in fexum fequiorem poteftatem exercent; quin fpretas ac defpectas uxores non folum ad viliffima, eaque moleftiora officia adi- 
gunt, fed et matrem feptennes pueri impune conviciantur aut fcelefta manu feriunt.

Corpus a frigoris iniuria pannis e phormio textis, plumisque avium aut pelle canina munitis tuentur. Sed igni circumiacentibus intra fumofa tuguria munditiae nulla cura eft cum $a b$ omni lavatione fqualidi atque pediculofi $a b$ horreant, nec non pigmento rubro et oleo rancido vultum foedare confueverint, ut hoftibus terrorem injiciant. Vi\&tus, quemadmodum fuperius monui, praecipuus pifculentus eft, pifcibus enim et recenter captis, et ad folem exficcatis vefcuntur. Docuit tamen etiam dira neceffitas ad fylvas confugere, filicumque radices medulla farctas effodere, dum vexatum procellis

\section{atrum}

defendens pisces hiemat mare.

Harum filicum in borealiori infula, quae populofior eft, cum ingentes acervos collectos vidiffet $\mathrm{Cl}$. Crozet, fimulque comperuiffet radicum Convolvuli, ari et diofcoreae culturam ibidem non plane negligi, hominibus Novae Zeelandiae victum vegetabilem effe nimis feftinanter inde collegit. Idem navarchus experientifilimus apud incolas iftius regionis frequen- . tem gummi cuiusdam calefacientis comiffationem obfervavit. Neque iam recufo, in calidiore Novae Zeelandiae parte, advenas e Zona torrida homines confuetudinem vegetabilis alimenti confervaffe; quin potius libenter concedam, hoc ftabili et minus erratico vitae genere effectum fuifle, ut numerus eor um magis 


\section{$\frac{\cos x}{m x_{0}}$}

accrefceret, civitatifque et regiae poteftatis primordia ibidem una progerminarent. Verum ex autoptarum confenfu facile colligitur, barbaros in boreali Novae Zeelandiae parte horrido carnium humanarum adpecitu, ferociffimo in hoftes animo, ad vindictam iramque pro. clivitate non folum auftraliores familias, mereque ichthyophagas aequare, fed et tanto iisdem praeftare, quanto in univerfum viribus corporis membrorumque immanitate eas antecellant. Qui ciborum ad animi adfectus excitandos potentiam agnofcunt huius tantae ferocitatis itimulos forte ab alkalefcente pifcium fubftantia petant, cum etiam in temperatiore infula, pifces faltim ex parte, hominum nutrimento infervire noverint.

Similem huic differentiam, quae inter diverfas nigrae gentis colonias intercedit, breviffimis verbis expediam. Ex his, qui Novae Caledoniae infulan aridam et montuofam incolunt homines reliquos manfuetudine pacifque ftudio fuperare videntur, Statura is aliquanto procerior, color fufcus quidem, fed ad caftaneum vergens: capilli torti, nec tamen plane ut in aethiope lanati. Eorum arva plantationi radicum ari et diofcoreaa idonea, in regione littorali, aquis marinis ftagnantibus fubinundata et rhizophorae, ficuumque radicantium denfo frutice intercepta, ligonibus fedulo confodiuntur. Soli fterilitas autem improbum incolarum laborem parce nimis remuneratur; quare et pifcatu vitam fuftentant, et ad fylveftria fuccedanea e regno vegetabili recurrunt, corticesque infipidos hibifci tiliacei exfugunc. Novarum

Hebri。 
Hebridum contra foecundifima tellus eft, quas fcilicet calor inteftinus vulcani non folum refociliet, fed et late difperfus laetificet cinis. Ibidem hortuli, quos indigenarum induftria plan. tavit, incra fpiffum undique nemus abfconditi latent, Mufae inprimis fruetibus, citro, ficubus edulibus, nucum vario genere, tum etiam ari et diofcoreae radicibus divites. If fa hinc inde farinofis onufta frudtibus artocarpus, licet minus frequens, confpicitur; domerticae porro volucres fuumque greges circa domicilia vagantur. Succurreret cuiquam forte illam naturae altricis ubertatem intuenti, ut in hisce infulis hominum firpem bene faginatam, corpulentam, fegniorem, imbellem, pacisque et veneris, otio quae maxime aluntur, artibus dedicam exfpeEtaret. Enimvero miraretur quod citra fpem illi obviam fierent (praeprimis in Malicollo infula) nigerrimi homunciones, nafo fimo, argulo Camperi acutiore $\left({ }^{*}\right)$, capillitio crifpo et lanato, exiles, macilenti, deformes, nudi, cingulo armillisque ftrictifimis coaretati, garruli, ingeniofi, aftuti, hiftriones, agiliffimi, irrequieti, furpiciofi, trepidi, fagittis clavisque perpetuo armati, mulierum ofores, anthropophagi! Quod vero infulae Tannae indigenis contigerit, mallicollenfibus ingenio magis mitescere, cosque proceritate corporis artuumque masculo vigore fuperare, id procul omni dubitatione, familiari quam habent cum quadam albidae gentis colonia confuetudini tri-

*) Ex occurfu linearum, alteritus ab ofre fiontali, alterins a meatu auditorio, ad dentes incifores fuperiores, ductarum. 

rire quidem, eoque machinam animalem perpetuo refarcire, fed pro diverfa principiorum in alimentis mifcela diverfffimum profecto habitum nancifci afferuerunt, cuius etiam in fenfus internos reactionem manifeftam fimili ratione contingere arbitrati funt, qua mutato inftrumentorum mechanismo, effectuum difcrimina in operibus humano artificio elaboratis plane deprehenduntur. Adduxerunt in huius doctrinae defenfionem exempla morborum varii generis, quorum fons et origo fublato elementorum noftri corporis aequilibrio debetur, fanandorum autem ratio in eodem mutata diaeta adhibitisque remediis efficacibus reftituendo confiftit. Tum in medium porro protulerunt animi affectus hoc vel illo cibo potuve interdum fopitos aut exfufcitatos; nec non denique inter tot gentium diverfffima ingenia, mitiflimum phytiphagis, atrox et bellicofum fola carne vefcentibus tribuerunt. Cum autem fingula, quibus haec opinio fulciri folet argumenta, poft Hallerum denuo recenfere $\left(^{*}\right)$ fupervacaneum et citra huius opellae propofitum foret, id unum, miffis coniecturis fallacibus adiiciam, ad immutandum typum varietatum humanarum, ex obfervationibus fuperius enumeratis, non adeo notabilem effe in terris auftralibus ciborum efficaciam.

Plantae in oceani auftralis infulis efculen: tae quinquaginta quatuor in univerfum mihi innotuerunt, quarum viginti fex ante noftum iter botanicis incognitae erant. Harum uni-

ver-

(*) Phyfiolog, Tom, VI, Lib. IX. Sect. 3. 
verfaliffimae funt, (cum etiam extra tropi-) cos reperiantur,) Convolvulus chryforrhizus, Diofcorea alata, Arum macrorhizon et eículentum; his proxime accedunt, tropico tamen inclufae: Mufa paradifiaca, Cocos nucifera et Artocarpus incifa; reliquae omnes in una alterave infularum congerie defiderantur, aut minus frequentes funt. Numeravi porro in Societatis infulis fpecies efculentas viginti fex; in amicorum infulis totidem; fed nonnullas diverfas; in novis Hebridibus circiter vigin$\mathrm{ti}$; in nova Zeelandia fedecim, quibus comprehenduntur antifcorbuticae feptem Europseis quidem pretiofiffimae, fed quarum apud incolas ad rem cibariam nullus eft ufus.

Erunt forte, qui in tenui laborem me collocaffe exiftiment. Attamen non defuit, qui ex hac tenuitate oriundam gloriolam legitimis dominis praeriperet, et alienae mefli immitteret falcem. Taceam rerum naturalium cognitionem, ufu femper effe anteriorem; et earum quae noftro itinere innotuerunt ad hominum neceffitates adplicationem, etiamfi parte faltem aequalibus noftris contingat, pofteritati tamen clariflime perficiciendain demum refervari.

Quod reliquum eft, quemadmodum adverfaria mea rurfus evolventi grata mihi erat abfoluti peripli commemoratio, ita fpero, mi 
lector, defcriptiones fequentes botanicas et tibi aliquam voluptatem allaturas, qua mecum gaudeas fruarisque.

Datum Vilnae Lithuanicae, anno MDCCLXXXVI.

D. GEORGIVS FORSTER. 


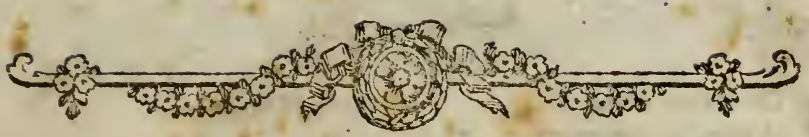

\section{A T A L O G V S}

PLANTARVM ESCVLENTARVM

AVSTRASIAE.

I. Fructus.

\section{Nomina}

1. Artocarpus incifa

2. Mula parad:fia a

3. Spondias dulcis t

4. Citrus Aurantium.

5. Citrus decumana

6. Eugema malaccenfis

7. Fi. us afpera $t$

8. Ficus granatum $t$

9. ficus indi a

10. Pandanus odoratifima

I1 Morinda citritolia

12. Solanum aviculare $\leftarrow\}$

13. Achras diffe $t a$

14 Crataeva religiofa t

15. Coriaria farmentofa t

\section{Clafles}

\section{Monoecia Monandria.}

Polygamia Monoecia.

Decandria Pentagynia.

\} Polyadelphia lcolandria。

Icofandria Monogynia.

7

Polygamia Trioecia.

Dioecia Monandria.

3 Pentandria Monoginia.

Hexandria Monogynia. Dodecandria Monogynia. Dioecia Decandria.

\section{Nuces.}

16. Cocos nucifera

17. Corypha umbraculifera. $\}$ Appendix Palınae.

18 'nocarpus edulis

Decandria Monogynia.

19 erminaiia Catappa

20 Jerminalia glabrata $t\}$

2I. Maba major t Polygamia Monoecia,

Dioecia Triandria.

22. Sterculir Bolanghas.

23. Sterculia foetida

? Monoecia Monadelphia.

3. Kadices.

24. Convolvulus chryforrhi- Pentandria Monogynia. zus t 
25 Diofores alata

26. Arum efulentun

27. Arum macroshizon

28. Tacca pinnatifida
Dioccia Hexandria.

? Gynandria Polyandria.

Dodecandria rrigynia.

29. Dracontium polyphyllum Gyrandria Polyandria. 30. Dgidgi ? radices 3I. Mawhaha $J$ radices

32. Dracaena terminalis. Hexandria Monogynia.

\section{Olera.}

33 Dracaena indivifa $t$

34. treca olerscea?

35. Areca fapida t

36. ipium giaveolens

37. etragonia halimifolia

38. ep diun oleraceum t?

39 Lepidium Pileidium $j$

40. Sonchus oleraceus

4I. Boerhava erecta 42. So'anum viride $t$ 43. Portulaca lutea $t$
Hexandria Monogynia.

? Appendix Palmac.

Pentandria Digynia.

Icolandria Pentagynia.

Terradynamia Siliculola.

Synzenefia $P$ aequrais. Monandria Monogynit.

Pentandria Monogynia

Dodecandria Monogynia.

5. Succedanea.

44. Avicennia refiniferat Didynamia Angiofpermia. 45. Hitifcus tiliaceuse 46. Coix Lacryma Monadelphia Polyandria 47. Pteris efculenta t 48 rolypodium medullare $t\}$ 49. Polypodium dichoto muin Monoecia Triandria.

Cryptogamia Filices.

\section{Potulenta.}

50. Piper methyfticum t

51 Sacchsrum officinarum

52. onvolvalus Turpethutn

53 Melaleuca foparia

54 Dacrydium capreffinum t Dioecia.
Diandria Trigynia.

Triandria Digynia.

Pentandria Monogynia.

Icofandria Monogynia.

Signo t notatae in editione XIV. Syftematis Vegetabilium Linnari quae cura Cel, 10. Andr. Murrayi prodiit, non reperiuntur. 


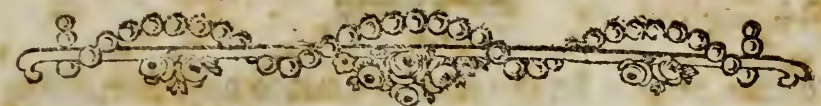

\section{Plantae Efculentae}

\section{Infularum Oceani Auftralis.}

\section{I. \\ F R V C T V S.}

I. A rtocarpus incisa. F.

A foliis incifis. M. S. V. p. 838. (Monogr. mea: vom Brodbaum 4to 1784 ).

Arbor craffitie hominis, altitudine quadraginta pedum et ultra, trunco ereeto, ligno molliori, levi, flavicante; libro efibrillis rigidiufculis reticulato, albo; cortice laevi, rimofo, pallide cinereo tuberculis exiguis raris afperfo. Arboris partes laefae omnes liquorem fundunt glutinofum lacteum.

Rami in comam amplam fubglobofam faftigiati, inferiores longiores, diftantia decem five duoB 4 decim 
decim pedum fupra terram e trunco prodeunt, fere horizontaliter patentes, fparfi, fubverticillati. Ramuli adfcendentes, apice floriferi, fructiferique.

Folia alterna, petiolata, ovata, fupra medium in lobos feptem novemve lanceolatos acutos profunde diffecta, finubus rotundatis; caeterum integerrima, utrinque glabra, laevia, patentia, laete virentia, fubtus pallidiora, membranacea, fesquipedalia, undecim pollices lata, venofa, nervis craffis, numero loborum e rachi communi excurrentium. Folia juniora ficut partes omnes teneriores arboris tacku glutinofa funt:

Petioli teretiufculi, laeves, adfcendentes, bipollicares. Stipulae binae, folia juniora involventes, lanceolatae, acuminatae, concavae, integrae, intus laeves, extrorfum pilofae, deciduae, tripollicares.

Pedunculi in apice ramulorum, et axillis foliorum fummorum folitarii, teretes, pilis raris confperfi, erecti, bipollicares.

\section{o Flores Mafculi ad folia fumma:}

CAL. Spathae nullae. Amentum fubcylindricum, clavatum, carnofum, crectum, fpithameum, flofculis feffilibus, exiguis innumeris, tectum, caducum. Pcrianthizm proprium minimum, bivalve, valvulis aequalibus, oblongis, obtufis, concavis, arcte cohaerentibus, claufis, luteo fufcis.

cok. nullá.

STAM. 
sTAM. Filamentum unicun breviffimum in fun. do perianthii. Antbera erecta, oblonga, fimplex, longitudine filamenti.

․ Flores Feminei in apice ramulorum.

CaL. Spathac bivalver, ovato-lanceolatae, compreffae, acuminatae, erectae, apice inflexae, molles, fpithameae, primum claufae, deinde deciduae, in apice pedunculi. Spadix? globofus, germinibus plurimis connatis tectus. Perianthium nullum.

$\left.\begin{array}{l}\text { cor. } \\ \text { stam. }\end{array}\right\}$ nulla.

PIST. Germina numerofa, obverfe conica, connata, receptaculo innata, apice convexiufcula, fingula fuperficie fubhexagona. Styli vix ulli, brevifimi fimplices, numero germinum, folitarii. Stigmata, puncta, prominula, marcefcentia, (in aliis varietatibus, bifid; Thunberg).

PER. Bacca globofa, glabriufcula fuperficie hexagonis conferipta, pallide virens; maxima dodrantalis pulpa farinacea, alba, fubfibrofa, maturitate fuccofa, flava; receptaculo clavato, carnofo, longitudinaliter. fibrofo, palmari, adnata.

SEM. (in hac varietate). Rudimenta fterilia, minuta, oblongiufcula, emarcida, fufca, apice pilo decies longiore coronata, pulpae immerfa.

Varietates praecipuae huius arboris duae funt

a) Fructu apvreno; haec iterum in quinque ordines difpefcitur quarum nomina lingua. taheitenfium vernacula funt fequentia:

B. 5

a) 
a) Uru, fructu apyreno glcbofo, laevi, muticc; vulgatiffimae, quam modo adumbravimus; varietati proprius.

b) Maira fru民u apyreno ovali, mutico, foliis profundius diffectis.

c) Patea, fructu apyreno, oblongo fcabro, quaif fquamolo.

d) Tatarra, fructu apyreno, ovali, germinibus verrucofo mami!laribus ftylo perfiftente muricatis; his accedit

e) Soccus lano/us Rumph. herb. amboin. I. tab. 32. fructu apyreno muricato, intus lanato - $\mathrm{fi}$ brofo.

B) Fructu feminifero, cuius defcriptionem dederunt Rumphius et Sonnerat. Haec olim in Taheiti infula cum praecedente reperiebatur, fed progreffu temporis neglecta periit, quum apyrenae varietatis ad rem cibariam praeftantior fit ufus. Semina magnitudine fere caftaneas exaequant, oblonga, fubangu ofa, utrinque in acumen producta, tunicis propriis, brunnea et alba, corticata, fingula interftincta membranulis five tunicis pluribus (e germinum abortu) et carne minus abundante fuccofa.' Hacce femina in primis Ce'ebae infulae hominibus pro a imento praecipuo inferviunt, qui eadem cinere fervido tofta, vel in aqua cocta, vorant.

Apyrena artocarpi varietas conjungtim cum feminifera adhuc in marianis infulis reperitur; in novis porro Hebridibus ac in amicorum archipela- 


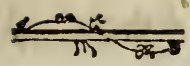

go, licet rarior, occurrit; copiofiffima autem omnium in focietatis et marchionis mendozae infu is, atque fatis abunde in Sandvigiis nonnu is co itur. Vidi etiam feme artocarpi ffirpem. juniorem in arboreto quodam novae Caledoniae, ubi inter rariffimas procul dubio recenferi debet.

Fructus hicce apyrenus perfecte maturus, pu'pofus, dulcefcens, facile putrefcit, atque tum alvum fertur nimis laxare; immaturus vero farinaceus eft, et in fornace fubterranea, vel etiam fuper igne toftus, faluberrimum et gratiffimum nutrimentum praebet, fapore panis triticei non adeo diffimile, tametfi cum radicibus helian thi tuberofi five etian fola. ni tuberofi quandam fimilitudinem habeat. Octo con. tinuis menfibus taheitenfes et adiacentium infularum marchionis incolae hocce inprimis cibo vefcuntur, neque per reliquos quatuor menfes, a Septembre in finem Decembris, fub ipfo inforefcentiae et groffificationis tempore eodem prorfus carent, cum loco recentis fructus maffam pu pae, fermentatione acidulatam, in panis fpeciem coquere probe norint, eamque in deliciis habeant. Liber arboris ad rem veftiariam pari modo, quo mori papyriferae liber, adhibetur; lignum pro cymbis, domibusque exfruendis; amenta mafcula pro fomite igniario; folia pro cibis involvendis manibusque abftergendis inferviunt. Succus lactefcens glutinofus coquendo infpiffatur, et in vifcum avibus capiendis idoneum convertitur; idem admiftum aliis ingredientibus gluten præbet, quod hydriarum fiffuris illini folet. Trium arborum annona ad alendum unum hominem fufficit.

2. MV - 
2. MVSA faRAdisiaca. Linn.

M.(Paradifaca) fpadice nutante, floribus màfculis perfiftentibus. M. S.V. p. 202 . n. I.

M. (Sapientum) fpadice nutante, floribus mafculis deciduis $M . S, V$. p. $9 \circ 2 . \mathrm{n} .2$.

Planta culta per totius orbis regiones calidas, in america ante hifpanorum adventum ignota, e guinea ad americae infulas aequinoctiales primum allata, in oceanum pacificum una cum hominibus ex orientali India migraffe videtur, ibidem enim in omnibus infulis, praeter demerfas et defertas, paffim colitur, et in varietates praefertim in archipelagis amicorum et focietatis numerofas degeneravit. Propagatur e radice et fto:onibus, foveae immiffis, cum cinere herbisque concrematis, quibus ca cis e conchis interdum pauxil um adjici folet, ut fructus cito progerminent, hae praecociores varietates menfe fexto, immo quarto nonnun-1 quam fructus proferunt, reliquae racemo nonnifi polt decimum octavum menfem onuftae ccrnuntur. Fructificatione peracta, tota ftirps, excepta tamen radice novos agente furculos, emoritur.

Fructus, prout diverfa eft varietatum indoles, a] ii crudi alii nonnifi tofti five affati comeduntur; horum priores hortorum taheitenfium praecipuum ornamentum conftituunt; pofteriores vero, utpote frigori magis affuefacti, in montuofis infu arum tractibus, locos nemoribus undiquaque claufos occupant. In moluccano archipe ago, pu'pam tofam horum fructuum mafticando in pu tem reducunt matres, quam infantibus etiam nolentibus in 
os ingerunt, eosque ut offam deglutiant variis artibus cogunt. Cibus eft facilis digeftionis, iis qui e onginquo itinere maritimo adpel unt maxime faJutaris et de'icatus; mihi tamen, propter naufeofam glutinofamque du cedinem femper iniucundus. Vifcida haecce qualitas videtur ftomacho debiliori infenfa, conftipat a'vum, flatusque gignit. Rumphius etiam maturos crudosque mufae fructus, cum facile putrefcant, in dyfenteria epidemica, malignitatem humorum adaugere credidit. Idem indefeffus naturae obfervator, in mo uccano archipe ago fedecim mufae varietates enumerat, quarum p'urimae etiam in auftrafiae infulis reperiuntur: ens vero verbis exprimere, vel differentiam fpecificam veram qua Mufam paradifiacam a Mufa fapientun dignofcere liceret, me nondum reperire potuifie, lubenter fateor. Figuras enimEhretianas a Rheedianis (Trew. t. 21. 22. 23 et Hort. Malab. p. I. t. 12. 13. 14). nihil difcrepare quis non videt, licet $b$. Linnaeus itlas Mufae fapientum, has vero paradifincae tribuerit?

I. Mufa corniculata, (Pifang Tando) cornu bovis figura et magnitudine fructuum aemulat; variat fructibus mollibus flauis, quos femineos vocant, et mafculis dictis, duris, viridibus, longioribus, aufteris, ut nonnifi tofti aut cocti menfae apponi queant. Singula bacca faepe duodecion pollices longitudine exaequat, brachii fere craffitiem adtingit; quare racemus fuffulciri folet, ne pondere fuo abrumpatur.

\section{Mufa ex/ucca (Pifang Gabba Gabba) parum} a praecedente differt, nif fructu tenuiore, ex albido flavefcente, fubftantia ficciffina, auftera, donec fub cineribus fervidis torreatur. 
III. Mufa tetragona (Pifang Cro) fructus gerit fpithameos, angulofos, plerumque tetragonos, extus virentes, intus albos, acidulos, duriufculos.

IV. Mufa acicularis (Pifang Dfiernang). FruEtus palmares, trigoni, acuminati, acumine longo filiformi, ftyli perfiftentis veftigio. Racemus feptem pedes nonnumquam longus eft, ducentos et quinquaginta fructus in feptemdecin verticillis non raro adnectens. Cortex, medullae rufefeenti et facchari inftar micanti, fortius quam in congeneribus adhaeret.

V. Mufa coriacea (Pifang Culit-Tabal). Cortex craffiffinus fruAus, recondit pulpam mollem, pallide rufam, pentagonam, ora interiore anguftiffima. Haec quoque frixa aut tofta folet menfis apponi, licet etiam cruda eadem in cibum cedat modo bene matura fit. Ad hasce quinque varietates, quibus etiam decima adnumeranda, taheitenfium varietates fylvaticae et montanae, quas libbi vocant, mihi fpectare videntur; harum maxima, maturitate extus et intus intenfe fulvo colore gaudet.

\section{Mufa menfaria (Pirang Medji). Hujus} fructus palmaris five fpithameus, teretiufculus, ftriis notatur quinque elevatioribus, obliteratis, inaequaliter difpofitis, vt fere trigonus appareat. Maturus e fulphureo colore flavefcit, facillime decorticandus, pulpa albida, fractura micante, fapida- dulci, ac fi aliquid aquae rofarum effet admiftum. Ad torrendum, nifi immoturus, non valet, féd crudus comeditur; facile putrefcit, cum et cito ad maturitatem perficiatur. Stipes altior quam in pluribus varietatibus; tolia fufco maculata. Haec impri- 


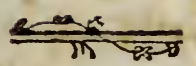

inprimis et proxima fequens, apud taheitenfes Meiya vocatur, vocabulo quod a voce malaica Medji parum abfonum videtur.

VII. Mufa regia, (Pifang Radja) gaudet fructu praecedenti affini, fed multo breviore, vix digiti longitudine, pollicem craffo, glabro, aequali, cortice tenuiore, fapore biulci et grato; quare a bataviae urbis incolis, maxime appetitur \& reliquis mufae varietatibus palmam praripit, menfisque crudus apponitur.

VIII. Mufa purpurafoens (Pifang Mera) forma fructuun cum $M$. regia convenit, colore differt; cum enim progerminent fructus externe purpureo fufci funt, croceo intermixto. Caro alba, acidula, edulis tamen fine praeparatione. Stipites, folia et racemi colore purpureo virenti inícsti funt.

IX. Mu Ja punctata (Pifang Salpicado). Fructus brevis, teretiufculus, flavus, minute nigro punctatus: cetera cum $\mathrm{M}$, menfaria conveniunt.

X. Mufa dorfata (Pifang Swangi). Fruclus craffus, fex pollicaris, protuberantiis longitudinalibus inaequaliter angulofus lateribus irregularibus. Pulpa intenfe lutea feu rufa, duriufcula mucofa, acidula, fubauftera; qua nec frixa, nec cruda vefcuntur homines, ad pultem tamen pro infantibus ufurpatur, et omnium viliffima habetur. Stirps reliquis altior.

XI. Muja granulo/a (Pifang Batu five Bidji); figura praecedentis, teres, tenuior, virens,' pulpa lmucofa, molli tamen et dulcefcente, repleta feminibus duris, nigricantibus inftar paconiae feminum. Stipes altus, per furculos adeo multiplicatur ut brevi tempore magnum fpatium occupet. Linnaeus hanc varietatem Mufae Troglodytarum adnuinerat. 
XII. Mufa fatua (Pifang Alphuru) fructus geri paruos, craffos, tereti compreffiufeulos, cinerafcen. tes, vifcolos, faporis fatui, toftos tamen bonos.

XIIr. Mufa coarctata (Pifang Bombor) ef fructu breuifimo, ovi gallinacei magnitudine, glabro, tetragono, apice obtufo, crudo eduli.

XIV. Mufa papillofa, (Pifang Suffu). Minores quam M. menfaria fructus gerit, pollicem craflos, angulofos, apice papillaeformi, flavefcentes, pulpa duriufcula, acidula, vili, quae torreri potius debet, quam cruda comedi. Folia huius varietatis tenella, farina quafi confperfa funt, qua abrafa, color fufcus adparet, qualis et deglupta extima membrana in ftipite confpicitur.

XV. Mufa pumila (Pifang Kitfil) Stirps humilis, cum foliis humanam altitudinem non excedit. FriClus rotundi, digiti longitudine, fed crafiores, extus lutei, glabri, corrice tenui fragili, Pulpa dura, acidula, tamen ut fertur, grata, et ficuum faporem fufcipiens fi fuerit in aqua cocta. Racemus licet humilis tamen ufque ad ducentos fructus non raro profert. Haec varietas gaudet folo pingui, terraque daedalaca, lapillis' mixta, atque hortos montanos amat in fyluis abfoonditos. Mufae reigae degenerem filiam putat Rumphius.

\section{Mura lunaris (Pifang Bulang - trang).} Huius racemus, ftipes, folia flaua funt, fruchusque albidi, ita ut nocku, lunae radiis illuminata, tota ftirps fimilem colorem reflectat, unde nomen malaicum nacta eft. 
3: SPONDIAS DULCIS. F.

S. petiolis teretibus fexjugis: foliolis ferratis, coftatisque $\mathrm{F}$.

Arbor procera, umbrofa, coma pulcra, late diffufa. Truncus craflitie, corpus humanum fuperat, erectus, ramofis, quinquaginta pedum altitudine, quotannis ante nouam foliationem florens, menfe feptembri.

Rami diffufi, patentes, teretes, cortice brunneo, fcabro. Folia (parfa, conferta, petiolata, pinnata, fexinga cum impari; foliola oblongo- lanceolata, acumnata, fubtiliffime ferrata glabra, patentia, coftata nerno marginali, venis plurimis fimplicibus parallelis rectis, a rachi media in coftas ad angulum rectum excurrentibus, faturate viridia, palmaria. Petioli communes, teretes, laeues, patentes, pedales; proprii fuboppofiti comprefliufculi, femipollicares.

Pedunculus in apice ramulorum uniuerfalis, terminalis, teres, laeuis, erectiufculus, longitudine petioli communis. Raccmus magnus compofitus. Pedunculi partiales alterni teretes, glabri, horizontales, fuperiores fenlim minores adfcendentes palmares; pedicelli vnifluri, fparfi breuiffimi. Flores parui, flavo - virentes.

CAL. Periantbium inferum, minimum, quinquepartitum laciniis aequalibus, acutis pallide viridibus.

Cor. Petala quinque lanceolata, patentifima, calycis laciniis interjecta, infera.

Nectarium? Annulus carnofus, torulofus, germen cingens, flauus,

C STAM. 
stam. Filamenta decem fubulata, petalis breuiora patentia. Artherae ouatae, erecto-incumben. tes. coalita.

PIsT. Germina quinque minuta, globola, bali

Styli quinque cylindrici, bafi approximati, apice recurvi, longitudine ftaminum. Stigmata ob. tula.

PER. Drupa oualis, obtula, magna, glaberrima, aurea, odore fub nauleofo foetida; putamine exteriore tenuifimo, punctato, acri, dentes arrodente, amaricante, pulpa carnola, fucculenta, dulci, acidulata, aromatica, fragrante. Nux in medio dura, lig. nofa, ouata, fibrillis duris pungentibus undiquaque echinata, quinquelocularis, diffepimentis membranaceis.

SEM. Nuclei folitarii, onati, comprefli, quamplurisnum abortiui.

Haec Ipondiae fpecies per focietatis et Amicorum infulas colitur, inprimis in Taheiti frequentiflima. Eius fructus fiue vere aurea poma in racemulis nutantibus proueniunt, et fapidifimis faluberrimisque ju- re adnumerantur, ejusdem fere ac Bromeliae Ananae tructus faporis, fitim non folum facile tollunt fedantque, fed etiam aegris, licet biliolis affectionibus et obftructionibus la'sorantibus, fine difcrimine conceduntur; aluum leniter referantes, antifeptici, et inter. horaeos fructus dignifimi qui principem locum occus pent. Nomen tahcitenfum $e \cdot V i$. Determinent alii, an haec noftra fpecies cum fpondia Myrobalano Linnaei, M.S. V. p. 428. n. 2. fue Celeberi. Jacquini fpondia Mombin conjungenda fit, nec ne. Si rectius fegre- 


\section{m}

Gavi, Linnaeanae fpecies novis differentiis fpecificis donandae funt.

\section{Citrus aurantium. Linn.}

C. petiolis alatis, foliis acuminatis. $M$. S. $V_{\text {. p. } 697, \text { n. } 2 .}$

Aurantia mala in novis Hebridibus reperiri anchor erat Petrus Fernandez de Quiros, primus harum infularum inventor, qui eadem terrae Manicolae, five Mallicullo tribuit. In hortis harum regionum littori vicinis tamen hanc arborem nufquam vidimus, neque forfen teftimunio nauarchi hifpani fidem adhibuiffesmus, nifi tandem in extrema huius archipelagi verfus anfrum potrecta Tanna infula, fructus aliquot inmaturos incolae femel venum obtuliffent, quos pro veris aurantiis agnouimus. Non igitur dubitandum eft, quin haecce hefferidum poma ab indigenis culta, rei cibariae harum infularum adnumeranda veniant.

\section{Citrus decuntana. Linn.}

C. petiolis alatis: folis obtufis emarginacis. M. S. V. p. 097 . n. 3 .

Frequentifluma eft in amicortum infulis arbor procera, uintrofa, pulchre comata, fioribus fragrantifimis, frućtibus maximis fapidiffunis fupcrbiens, qui belgice Pompelmoefen audiunt et inter congeneres omnium faluberrimi habentur. Hi fructus toti confant paruis folliculis, facile et quidem fine diruptione pelliculae feparabilibus. Apud incolas infularun E. uwa tine Medioburgi, Namoka fiue Rotterodami et Tongatabu fue Anftelodami, nonine Mcliya diftinguuntur. 
6. eugenia malaccensis. Linn.

E. foliis integerrimis, pedunculis ramofis lateralibus. $M . S$. $V$. p. 461.

Haec arbor plurimis infulis oceani aufralis intra tropicos communis eft, et praefertim colitur in ' $\mathrm{Ta}$ heiti, congeriebus infularum Societatis, Marchionis, Sandvigii, nouarumque Hebridum. Fructus albicans eft, rofeo tinctus, pyriformis, interdum pugni fere magnitudine, fed plerumyue multo minor, ex acidulo faccharatus, aqueus et fuccofus; falubris itaque et etiam aegros morbo inflammatorio decumbentes refrigeratione confortans. Corticem tritum et in lacte acido epotum Rheedius inter antidyfenterica laudat. (Hort. Malab. I. p. 30.) Nucleus in centro drupae folitarius eft; perperam Parkinfonius (Journal p. 4C) pericarpium feminibus farctum dixit. Arbor magna et procera, foliis maximis umbrofa, taheitenfibus Heiva vocatur. Dubito an praeter hancce fpeciem etiam Eugenia Jambos inter plantas infularum auftralium ciuitate donanda fit.

7. FICUS ASPERA. F.

F. foliis oblique cordatis, finuato-dentatis, verinque afperis: fructibus turbinatis, calycis margine obfoleto adnato. F.

Arbor quatuor fue quinque orgyarum altitudine, foliofa, ramis articulatis.

Folia alterna fubpetiolata, ouato- cordata, acuminata, finuato-dentata, difco interiore anguftiore, vtrinque afpera, pilofa, patentia, fpithamea. Petioli breuiflimi, alterni, fparfi, teretes, fuperius fulco exarati, 


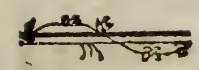

Receptacula axillaria, gemina, feffilia, turbina. to - globofa, extus fericeo-tomentofa, alba, magnitudine Ficus Caricae Linnaei, carnofa, fuccofa, fapida. Calyx communis nullus; fed margo obfoletus integer vix bi feu tridentatus, receptaculum in ea regione cingit, vbi magis dilatari incipit.

Colitur in hortis et arboretis Tannae infulae. Fructus dulces, grati, crudi comeduntur. Folia juniora cocta indigenis fapidum olus praebent.

Confer: Rbced. Hort. Mal. p. IIr. t. 62.

8. FICUS GRANATUM. F.

F. foliis outis integerrimis: pedunculis terminalibus, geminis horizontaliter divergentibus, fructibus calyculatis, glo: bofis. F.

Habitat cum pracedente in Tanna, fimiliter culta, propter fructum edulem, dulcefcentem, aquofum, fubinfipidum.

Arbo procera vimbrofa, caudice multangulo torofo. Rami omnes adfcendentes, longi, teretiufculi, fubarticulati, cinereofufci, inaequales, ramulis teretibus articulatis, apice tantum foliofis.

Folia conferta alterna, petiolata, ouata, integerrima, glabra, venis raris flauis, fupra intenfe viridia, inferne lucidiora, Spithamea et vltra, patentia. Petioli teretiufculi, glabri, patentes, longitudine quadrantis foliorum. Gemmae terminales arctiores fpiniformes, totae pilis badiis veftitae.

Pedunculi axillares folii fupremi et proximi, gemini, craff, breuiflimi, teretes, horizontaliter diuergentes. 
Receptacula giobofa, magnitudine Ficus Caricas fuperant, fubpubsfcentia, rolea, maculis flauis confperfa, intus purpurea, pulpofa, mollia.

Calyx communis triphyllus, foliolis ouato fubro tundis paruis.

\section{FICUS INDICA? Linn.}

F. foliis lanceolatis, integerrimis petio. latis, pedunculis aggregatis, ramis radicantibus. M. S. V. p. 922. n. $\%$

Arbor in Tanna, nouarmm Hebridum infula, umbrofa, excelfa. propter fructus parvulos et infipidos colebatur. Hi ex codem puncto feu cicatricula caudicis plures aggregati proueniebant, ita vt totus truncus iisdem confitus effet. Defcriptionem huius fpeciei ex meis Schedis deperdidi; an cum Ficu indica Linnaei merito conjungenda frt, etiamnum dubito. Eursclem forte fpeciei eft Ficus in 'Tongatabu fponte nafcens, cuims fructibus Cerafi minoris magnitudine incolae vefcebantur, et iisdem nomen Matte imponebant, quod in o. "Taheiti diuerfae prorfus Ipeciei, nempe F. tinglorias proprium, Cook. it。 nouiff. Vol. l. pag. 332.

10. pandanes odoratissima. Linn. $M . S$. p. 878 .

\section{Athrodadylis fpinofa Forfl. Charat. gen. 75 .}

Radix. Caudices plures defcendentes, divergentes, altitudine femiorgyali fupra terram clevati, fimplices, teretes, glabri, brachii crafitie, apice, vbi terram intrant, fibris aliqurot praediti. 
Truncus arboreus bi feu triorgyalis, craffitie fe. moris, teres laeuis, annulis eleuatis approximatis notatus, erechus, interdum ramofus, cortice tenui cinereo, ligno fpongiofo. Rami fubdichotomi, eredo patentes, faepe diuaricati, teretes, e cafu foliorum annulati, apice foliofi.

Folia terminalia confertifima trificha vel tetrafticha, feflilia, enfata, longiffima, acuta, extus carinata, aculeis antrorfum verfis confertis in margine et carina vndique fpinofa, venis transuerfis rectis carinae perpendicularibus notata, glauca, tripedalia, bafi binos pollices lata.

Pedunculus terminalis, nutans, teres, glaber, bipedalis, Thyrfo decompofito, çandido, pedunculis partialibus palmaribus, teretibus varie ramofis glabris, pedicellis pollicaribus, teretibus, erectopatentibus, ttaminibus confitis.

ơ. Flores mafculi. Bracieae alternae, lanceolatae, tencrae, erectae, margine ferratofpinofae, candidae, fefquipedales, florum thyrfos colligentes, loco fpathas.

$\left.\begin{array}{l}\text { CAL. } \\ \text { COR. }\end{array}\right\}$ nulia.

STAM. Filamenta plurina (duodecim ad triginta) pedicellis fparfim infidentia breviffima. Antberae oblongae, acutiufculae, erectae, filamentis multo lon. giores.

9 Flores feminei in diverfa arbore. Folia terminalia quatuor enfata, dorfo et margine ferrato fpinofa, pedalia, conniventia, fpatharum vices agunt.

$\mathrm{C}_{4}$ CAT 
car. Spadix terminalis fubglobofus fructificationibus numerolis tectus, viridis, fpathis non inclufus. Perianthium nullum.

cor. nulla.

PIST. Germina numerola, cuneiformia, apice convexa, interdum tuberculata, receptaculo conico five globofo infidentia.

Styli? rudimenta aliquot breviffina, in apice cuiusvis germinis vel e centro prodeuntia vel etiann in quolibet tuberculo germinis, folitarie difperfa.

PEr. Fruetus fubglobofus, maximus compofitus. Drupae numerofac, cuneate, apice convexae, lateribus angulofae; farinaceae, mon "permae.

sE.M. Solitarium, ovale, laeve, magnitudine nuclei olivae, in centro cuiusvis drupae.

Varietates: a) fructibus tuberculatis difcretis. Hort. Mal p. ji. t. 6.

B) fructibus convexis apice difcretis, $H$. M. p. ij. t. 7 .

y) fruftibus convexis, trifulcis connatis. H. M. p. ij. t. 5 .

d) fructibus convexis fpinofis umbilicatis congeltis. H.M. p. jj. t. 8 .

Arbor littorea, fabulofa amans, fponte crefcit in oris maritimis infularum fere omnimm intra tropicos, etiam demerfarm; fructu et foliis Bromeliae quodammodo fmilitudinem prae fe fert; candice fingulari, apice tantum frondofo, palmis affinitate jungitur eodem ac forte snaisri jure quam Stratiotes et Vallifneria. Flores inafculi pollent odonc fragrantiflino, 
fed dantur etiam varietates inodorae. Arabes et Zey* lonenfes prepter hunc odorem Pandanos mafculas colunt; Indorum mulieres, praefertim infulas orientales in habitantium capillos polline antherarum odo. ratifimo confpergunt; folia foralia autem et thyrfi racemulos in ciltis inter veftes reponunt. Ternatenfes eosdem flores nondum apertos cum carne et pifcibus oleris loco coquunt. Bandanenfes folia vulneribus imponunt, in anfralis autem oceani infulis ftoreae inde fiunt. Fructus in India ab Elephantibus vorantur; in o. Taheiti et circumjacentibus infulis a pueris exfun gillari folent; fi Artocarpus defecerit, etiam adulti iisden vefcuntur. Sunt colore extrorfum toti aurantii, intus flavi, odorem gratiflimum et aromaticum fragorum vel Bromeliae Ananae fpargunt, fubftantiam pulpofo- farinaceam, faporis primum dulcefcentis deinde adfringentis aufteri: vires ftypticas is ineffe docuit Rheede in Hort Malab. Fructus taheitenfibus e-Vara; flores malculi Hinanno.

\section{I. MORINDA CITRIFOLIA Linn.}

M. arborea, pedunculis folitariis. M. S. $V$.p. 217 .

Inter fructus edules infularum auftralis oceani fuccedanei locum occupant huius arbufculae baccae, quae Taheitenfibus Nono vocantur, et pro cibo vfurpantur deficiente artocarpi annona. Ex Cookii novifli. mo itinere cognovimus hofce fructus, qui crudi viridi - flavelcentes, aquofi et infulfi funt, coctos, five - in fornace fubterranea affatos, faporem gratum acquirere. Haec Morindae fpecies in hife regionibus fpontanea eft, cum paflim et quidem in defertis etiam infulis reperiatur. Baccarum vires anodynas laudat. Rumphius in Herb, amb. jij. p. 159. 


\section{2}

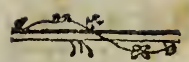

J2. Solanum aviculare. F.

S. caule inermi fruticofo, foliis finuatopinnatifidis: corymbis terminalibus. F.

Huius baccae fulvae, pruni majoris magnitudine, acidae, parum dulcefcentes fubnaufeofae, ab incolis Novae $Z$ eelandiae avide vorantur, aviculis etiam gratiffinae neque noftratibus omnino rejiciendae. Habitat fponte in Novae Zelandiae dumetis ruderatisque.

Caulis fruticofus, eredus inermis ramofus, femiorgyalis. Rami herbacei, laeves, fubteretes, craffitie fere digiti, breves.

Folia aleerna, petiolata, fimuato - pinnatifida, inferius acuminata, pedalia, laciniis lanceolatis oppofitis, trium parium cum impari, lacvibus integris, faturate viridibus, palmaribus. Perioli feniteretes, lacves, patentes, Iparfi.

Corymbi terminales duo five tres, pauci-flori. Pedunculus vniverfalis teretiufculus erectus, palmaris; partiales fex feu feptem, fparfi uniflori, teretes, laeves, patentes, elevatione proportionali, pedunculo univerfali quafi per articulationem impofiti. Flores violacei, pollicares, Aaminibus flavis.

Cal. Periantbium turbinatum quinquefidum, laciniis brevibus acutis.

CoR. monopetala plicato - rotata, tubo brevifimo, laciniis quinque margine plica auctis.

SтAм. Filamenta quinque corolla breviora. Ane. therae in tubum conniventes.

PIST. Germen oblongum. Stylus longitudine Raminum. Stigma breve bilabiatum. 


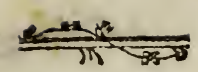

PER. Bacca ovalis, aurea, bilocularis.

SEM. plurima nidulantia.

I3. ACHras Dissecta F.

A. floribus confertis, corollis octodecimfidis: foliis obovatis emarginato - recu- fis. F.

A. diffecta. M. S. V.p. 342, Linn. Suppt. pl. p. 210.

Manyl-kara. Rheed. Hort. Mal. part jji. p. $53 \cdot$ t. 25 .

Advena in hortis Malabarorum colitur nomine Manylkara, five Karae manilenfis, cum ex infulis philippinis allatam adfeverent. Fructus huius arboris eft pomum, forma et magnitudine olivae, oblongum, viridinitens, vifcido et lacteo fucco refertum, maturius purpureum, intus rufum, fucculentum, carne acido - dulci, femen unum alterumve continens (reliquis loculamentis abortientibus), nucleo albo amariufculo. Hi fructus ibidem inter bellaria comeduntul. Folia cum curcumae radice et zinziberis foliis cocta et contufa ad cataplafma contra tumores adhibentur, Brachmanis Manil-gale (fed in tabula aenea nomen adfcriptum Vanvalli), Lulitanis Fruita Ma. millha, Belgis Loe - beffen five chineefche pruynen vocantur; quod etian apud Sinas crefcant. Arborem pro. cerain, caudice craffo, ramis longe lateque comatam dixit Rheede. Mihi femel vifa eft in Tongatabu infula, menfe Septembri florens; fructus autem tune temporis nullos perficiebat. E fpecimine ficco, quod pater optimus nobiliffimo D. Baeck, Regis Sueciae Archiatro cum plurimis aliis dono miferat, Linnaeus, filius, defcriptionem, quamvis imperfectam collegit, fimul 
fimul et nomen refcivit, quod huic plantae impolueran; inventorem inside fedulo reticuit.

Caulis arboreus, erectus, cortice cinereo-rufecente, tuberculato tectus. Rami lignofi, horizontaliadfcendentes, teretes, tuberculati, culitales (in noftro fpecimine). Ramuli erecto - adficendentes, fecundi, teretes, tuberculati, apice foliofi, fpithamei,

Folia fparfa, conferta, petiolata, oblongo - obovata, apice fubemarginata, integerrima, ereço - patentia, glabra, coriacea, fupra dilucide virilia, fubtus pallidiora, bipollicaria. Petioli teretes, tenues, erccto-patentes laeves, fere pollicares.

Pedunculi uniflori conferti, vndique e ramulis inter folia prodeuntes, filiformes, patentes, faepe horizontaliter-dependentes, numerofi, longitudine petiolorum. Flores albidi diametro femipollicari.

CAL. Periantbium hexaphyllum, patens; foliolis ovatis obtufis, tribus exterioribus viridibus, interioribus tenerioribus albis.

Cor. monopetala , oftodecimfida. Laciniae fex majores lineares erectae, lateribus involutae, calyce longiores, ftamina ante eruptionem foventes; duodecim dimidio minores, per paria inter majores pofitae, lineares, acuminatae, extrorfum revolutae. Nectaria e foliolis fex ovatis acuminatis inter lacinias majores corollae ad bafin minorum pofitis, crectis.

STam. Filamenta fex, fubulata, erecta, ante apicem parum inflexa, longitudine calycis. Antberae incumbentes, lineares, acutae, bafi bipartitae.

PIST. Germen fuperum, exiguum, multiloculare. Stylus corolla longior, filiformis, parum curvatus. Stigma capitatum. 


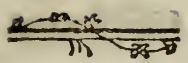

PER. Inon vidi, fed baccam live pomun e ger-

SEM. $\left\{\begin{array}{l}\text { mine fieri ut in congeneribus, ex defcrip- } \\ \text { tione Rheedii conftat. }\end{array}\right.$

Partes herbaceae huius arboris omnes lactefcunt. Inter,fpontaneas harum infularum retuli, infcius, an fructus $\mathrm{ab}$ inculis pro cibo ufurpentur.

I4. CRATAeva Religiosa. F.

\section{C. inermis, foliolis aequalibus $\mathbf{F}$.}

Reperitur ad Coemeteria infularum n. "Taheiti et Societatis, culta et deorum numini facra. Fructus profert minus fapidos, edules tamen, quales Crataeva Tapia Linnaei, tefle Rheedio; huic fpeciei etian nimis affinis eft; an cum eadem vltro conjungenda fit, dijudicent qui Tapiam obfervarunt. Noftra apud taheitenfes $\boldsymbol{e}-P u r a-a u$, five $P$ urataruru vocatur.

Truncus arboreus, mediocris altitudinis, erectus, ramofus. Rami patentes, teretes, adfcendentes, lignof, cortice oliuaceo, punctis elevatis albidis afperfo.

Folia fparfa, petiolata, ternata: foliola ovatolanceolata, acuta, acuminata, integerrima, glabra, tenera nervis venisque plurimis reticulata, fpithamea; lateralia parum minora margine antico anguftiore (fed non breviore) horizontaliter patentia. Petioli communes fparfi, patentes femiteretes, laeves, palmares; partiales breviffimi.

Cyma terminalis fubcorymbofa, femipalınaris; interdum flores folitarii ex axillis foliorum fummorum. Pedunculi vniflori teretes, laeves, laxi, palmares, patentes, bafi craffuufculi: Flores fesquiunciales, cxalbido virentes, ftaminibus rubicundis.

CAL. 
CAL. Periantbium margine inflexo receptaculum bafi umbilicans, quadrifidun, laciniis lineari-oblongis, acutis, longitudinaliter rugofis.

cor. Petala quatuor (demto coiore folia perfecte mentiuntur) erecta, ovato lanceolata, integerrima rachi dorfali venisque reticulata, laxa, tenera, candida, bipollicaria ; unguibus calyce vix brevioribus, virentibus intus canaliculatis, extus convexis.

STAsr. Filamenta fedecim, filiformia receptaculo inferta (nec gynandra) erecto patentia, pctalis paullo longiora. Antberae oblongae, verfatiles, inclinatae, e flavo rubicundae.

PER. Germerz oblongum, pedicello longitudine ftaminum filiformi elevatum. Stylus nullus, Stig* 'ma fefile, plenum, obtufum.

FER. Bacca? oblonga, bivalvis?' unilocularis, pedicello ad palmarem longitudinem elongato infidens.

SEM. oblongo - ovata, parieti valvularum, affixa, -

I5. coriaria sarmentosa. F.

C. procumbens diffufa, foliis cordato. ovatis acuminatis integerrimis quinquenerviis, fubpetiolatis: racemis axillaribus elongatis nutantibus. F.

Habitat fponte in fruticetis et dumetis Novae Zeelandiae. Barbari huius regionis incolae, inprimis ii, qui portum obfeurum (Dufky bay) accolunt, baccatos fructus huius fruticis colligunt, et iisdem, vefcuntur.

Cau- 


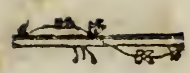

Caulis fruticofus, vix arborefcens, diffufus ramo. frfumus, frmentis elongatis decumbentibus, tetragonis, laevibus, virefcentibus, foliatis.

Folia oppofita fubcordato - ovata, fubpetiolata, inferiora fubféfilia, omnia integra acuminata acuta, horizontalia, laevia, quinque-nervia, palmaria. $\mathrm{Pe}$ tioli teretiufculi brevifimi。

Pedunculi axillares foliorum fuperiorum, folitasii, reclinati, fpithamei; racemus fumpliciffimus longus cylindraceus nutans, pedicellis unifloris fparfis, teretibus, filiformibus, laevibus, erectis, lemipollicaribus, bracteatis.

Bracteae breviffumae sninimae ad bafin pedicellorum extrorfum pofitae folitariae. Flores minuti virides, hermapsiroditi.

Cal. Periantbium inferum, perfiftens breve, quinquepartitum, foliolis fubrotundis concąvis adpreflis.

Cor. Petala quinque viridia, ovata, patentia, calycem longitudine aequantia.

STAM. Filamenta decen capillaria corolla longio. ra. Antherac ovato-erectae, longitudine calycis.

PIST. Germina quinque depreffo- coalita. Styli quinque filiformes acuti, patentes reflexi decidui, longitudine faminum. Stignata fimplicia.

PER. Bacca globofo - depreffa, quinquepartita atro-purpurea, e petalis carnofis, conniventibus, temina tegentibus.

SEM. quinque reniformia, Ariata, glabra. 
Nobis haecce fpecies femper floribus hermaphro. ditis vifa of nufquam vero mafculi aut feminei feorfim reperiebantur.

\section{II. \\ N U C E S.}

16. cocos NuCifera Linn.

C. inermis, frondibus pinnatis: foliolis replicatis enfiformibus. $M$. S. $V$. $p$. 985. $\mathrm{n} \mathrm{I}$.

Infulae oceani aufralis quae intra tropicos fitae funt, fere omnes hane utilifimam palmam ferunt, humiles etiam illae, quae vix fuperficiem fali fupereminent et lithophytorum aedificiis fuperftruckae funt, ut plurimum harun arborum altiflinarum coma condecorantur. Spontaneis igitur harum regionum vegetabilitus easdem adnumerare non dubitamus, licet etiam cultae ibidem dentur varietates, quas ut exempla in novis hebridibus docent, hominum cura nobilitavit, et praefertim ad rem cibariam meliores reddidit. Hasce varietates notis exterioribus tamen minus ab invicem dignofcendas, difertis verbis enarravit Clariffmus Rumphius, qui fimul de ufu harum arborum multifario fufius differuit. Heic loci meminifle fat erit, nucibus Cocos triplex ineffe alimentum, nempe junioribus lympham faccharatam, maturo fructu in materiam fpongiofam cotyledonis novi furculi coagulabilen; in adultioribus autem nucleum candidiflimum dulciflinum fragrantem, amygdalos longe praecellentem, primum mollem gela. tinofum lacteum deinde perfecta maturitate duriufcuLum, oleofum, ultimo deinceps loco iplim huius nuclei ole- 
oleum, blandum, purum, dulce, variis ferculis ad. mifcendum, nec non ad ufus medicos cunctos idone. uım, ubi oleum anygdalorum adhiberi lolet. Incolae praeprimis infulae Taheiti et adjacentium infularum Societatis hocce oleum imbutum odoribus variis; quorum pretiofiflimus, et fragrantiffimus e ligno Santali extrahitur, pro unguento caefariei five etian totius corporis ufurpant, codemque omnia membra crebro perfricare folent. I Ifum nucis putamen, duriffimum in adulta, in juniore tamen ante nuclei formationem molle, inftar caulium braflicae edule eft. Omnium porro palmarum cor five caput ut vocant, ad trunci fummitatem, pedes binos vel tres longun, rudimenta frondium et fructificationum anni infequentis laminis tenuiffmis convolutis fovens, itaque pro gemma vere hahendum, optimum alimentum praebet, nuci coryli avellanae et pedunculo brafficae cauliflorae palmam eripiens; fed hoc fine arboris deftructione obtineri non poteft. De vino palmarum quod colligitur e fpadicis nedum erupti vulnere, cum id hominibus auftraliae hand innotuerit, ut et de multiplici materiei, frondium, foliolorum, fibrarum, nucumque ad rem familiarem et mechanicam ufu quaecunque differi poffent, utpote citra noftrum propofitum praetermittenda funt. Taheitenfibus $\mathrm{Ar}$, nuces juniores Nia.

\section{CORYPHA VMBRACVLIFERA Linn.}

C. frondibus pinnato-palmatis, plicatis filoque interjeßtis, ftipitibus ciliato - fpinofis. M. S. $V$. p. 984 .

Huius folium femel vidi in Waitahu, five Chri: ntinae infula archipelagi marchionis mendozae; palmam ipfan deinde, fed minus frequentem in Tonga- 
tabu, amicorum infula reperit Cookius (vide Itin. no: viff. Vol. I. p. 332.) incolis Biu dıctam, quà nuces eius globolas parvulas inter edulia habent.

\section{INOCARPVS EDVLIS. F. $M S . V \cdot$ p. 408.}

'Taheitenfes huius arboris fructum Rattá vocant, ipfam arborem $H i$ appellant, quod a voce If apud Papuanos in Nova Guinea ufitata non admodum differt; nuces $E$ - ifi, quas Cookius in novilfimo itinere Tom. 1. p. 393. commemorat, ad Inocarpum quoque procul dubio referri debent. Earum nucleus reniformis, compreflus, pollicaris circiter diametri, anlatus et decorticatus ab infularum Societatis, Amicorum, marchionis, novarum Hebridum, novae Guineae et moluccarum incolis comeditur. Noftrates hanc nucem caftanearum loco habebant; fapor tamen minus gratus eft, licet dulcefcens; fubftantia durior, minus farinofa, ventriculo debiliori non conducit. Vires plantae et praefertim corticis adftringentes, alvum obftipant, et dyfenteriam liftunt; quare etiam ad hunc fcopum in nofocomio amboinenfi decoctum aquofun corticis crebro adhibetur, tefte Rumphio; licet hoc medicamine aegrorum vita periclitari potius quam fanitas reftaurari videatur. Papuani fucco expr ffo glutinofo, refinofo telormm apices obliniunt, hoc autem gluten exficcatione nigrum colorem induit. Forte et refinofum illud, quo fagittas Mallicollenfum obductas vidimus et quod illorum aftutia pro veneno nobis venditabat, ex Inocarpi fucco pariter praepara tum erat. Nomen arburis apud Mallicollenfes Nias audit, apud infulae Tannae indigenas Emmer. Inocarpum arboribus cultis in hisce regionibus vix adnumerarem, etfi in focietatis infulis forte colitur. 
Arbor excella, craflitie corporis humani, cortice fufco rimofo. Rami lignofi tercres, patentes, varie divifi, fulci, rimofi.

Folia alterna fubdifficha, petiolata, ovato-oblonga, vix cordata, obtufa, retufaque, rarius acuta, integerrima laevia, patentia, venis plutimis reticulata, fpithamea, (juniorum artrosm pedalia). Petioli teretiufculi patentes, laeves, transverfin friati, femipollicares.

Yedunculi univerfales axillares, fubfolitarii, tereres, patentes pube nigra tecti, palmares. Racemus filiformis fimplicifiuntis. Pedicelli brevinfmi, fparf, conferti. Flores oblcure albidi, vix femunciales. NB. Racemus in Linn. Suppl. pl. p. 239. perperam Spica vocatur.

CA L. Periantbium monophyllum bifidum, laciniis fubaequalibus, rotundatis, pube nigra veftitis.

cor. monopetala tubulofa. Tubus cylindricus longitudine calycis. Limbus quinque vel fexpartitus calyce longior, laciniis linearibus undulatis patentireflexis.

Stam. Filamenta decem vei duodecin brevifima, tubo duplici ferie inferta, ordine fuperiore in ipfa fauce, cum inferiore alternante. Antberae parvae, ovatae, erectae.

PIST. Germen oblongum villofum Siylus nullus. Stigma? punctum exiguum excavatum.

PER, Drupa magna, reniformis vel ovata, compreffa viridis, monolperma, pulpa carnofa tenui.

$\mathrm{D} 2$ SEM, 


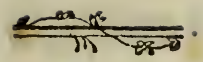

SEM. Nux folitaria, ovata, conftans e fibris lignofis, craflioribus intertextis: nucleo ovali, compreffo, albo.

OBs. Pili in germine, an fylorum vices agunt?

\section{TERminalia CATAPPa. Linn.}

T. Foliis obovatis, fubtus tomentofis. $M$. S. $V$. p. gro.

In hortis infulae Tannae femel hanc arborem vi. dimus, menfe Augufto five fub finem brumae foliis orbam, fructu maturo in ramulis haerente. Arbor erat vafta, et excelfa. Drupa tripollicaris, ovata, fulcata, nucleo oblongo, avellanae nucis fapore, quare etiam in Banda et Batavia inter obfonia cum aliis fructibus menfae apponitur, ab Europieis enim pluris exiftimatur, quam ab indigenis, quippe qui vilipendunt quicquid ventrem non adeo implet. $A$ pti funt hi nuclei, qui anygdalorum loco adhibeantur, fed oleo tam copiofo non pollent. Plantari folent huius generis arbores circa aedes in areis amplis, ubi fedilia eollocantur, propter denfam lateque extenfam quam praebent umbram. Materies exftruendis navigiis idonea, levis enim eft et in aqua marina per multos annos perdurat. Cortex et folia nigrum pigmentum praehent, quo dentes Indorum inficiuntur, nec non atramentum Indicum inde componitur. Hanc arborem ter fingulis annis maturos fructus perferre auctor eft Rheede.

20. TERMINALIA GLABRATA F.

\section{T. foliis obovatis, utriusque glabris. F.}

Differt a Terminalia Catappa, foliis in pagina inferiore pube deftitutis, duplo minoribus, nuce triplo 
plo minori glabra, ovali, minime fulcata, neque marginata, led apice acuto, compreffo et membranaceo quafi appendiculata: differentias effentiales curatior inflituta comparatio forte fuppeditaret; fed $T$. Catappam, ut fupra monui, nonnifi foliorum et flo. refcentiae ornatu fpoliatam vidimus.

Haec noftra fpecies autem colitur ad tuguria et coemeteria infularum focietatis; in amicorum infulis nihi fponte provenire videbatur. Taheitenfium lingua vocatur Aubiri, five etiam e-Tara iri et $e-T a$ ra-beiriri, diisque facra habetur. Materies pro exftruendis cymbis, tympanis, famnisque ufurpatur. Nuclei edules funt et inftar amygdalarum gratum fa. porem habent. Arhor ex elfa, ramofa, diffufa, ra॰ mis fuboppofitis, teretibus, patentibus, laeviufculis, cortice cinereo rimofo.

Folia terminalia, conferta, petiolata, ovata, ub. ovataque, obtufufcula, integerrima, patentia, glabra, laevia, fpithamea; petioli teretes, patentes, villo brevi rufefcente veftiti, vix unciales.

Pedunculi axillares foliorum fummorum, fimplices, teretes, filiformes, erecti, apice deflexi, glitbri, fpithamei Racemus fimpliciffunus, floribus fparfis albidis: mafculis in parte fuprema pedicellatis; hermaphroditis in parte infima fimillimis fed revera feffilibus, cum ipfum germen inferum vices pedicelli agat, reliquas partes fructificationis elevantis.

\section{or. Flores Mafculi.}

CAL. Periantbium campanulatum, quinquefidum laciniis ovatis, acutis, aequalibus, erectis.

cor, nulla. 
Nictarium urceolatum in fundo calycis, conftans corpufculis quinque minutis brevibus, duriulculis, pilis crebris longioribus veftitis, calyce dimidio brevioribus.

STAM. Filamenta decem fubulata, erecto patentia, fundo calycis inferta, horum quinque exteriora longitudine calycis, interiora minora. Antberae ovatae, didymae, erectae.

- ఫ્. Flores Hermaphroditi numerofi ufque ad dimi: diun racemun,

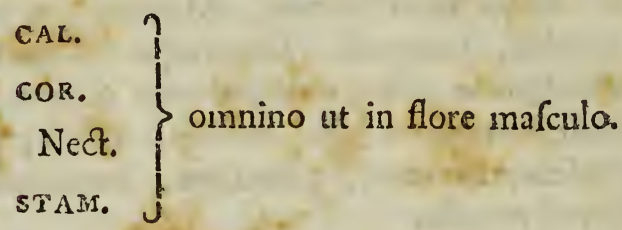

pist. Germen inferum, feffile, ovato-oblongum, bafi incraffatum. Stylus fuperus, e fundo calycis, villo reckarii cinctus, filiformis, erectus, longitudine ftaminum. Stigma fimplex.

PER. Drupa ovalis, fefflilis, acuminata, apice mareefcente, compreffa, viridis, inonofperma.

SÉM. Nux offea, ovalis, nucleo folitario, ob: longo, albo.

2r. Maba MATOR. F.

M. - - -

Huins fructus cum illo Mabae ellipticae noftrae in omnibus convenit, praeterquam quod triplo maior fit, bipollicaris feilicet, in loculamentis fowens nucleos triquetros, tenaces et infipidos, tamen inter edulia ab incolis ufurpatos. Incolae infularum Ton- 
gatabu, Namoka, E-uwa, Hapa-i, et ceterarum quae ad archipelagum amicorum pertinent, hanc arborem tefte Cookio in novif, itin. tom. 1. p. 393. circa tuguria plantare folent. Nobis non nifi drupa, $a b$ incolis iisdem venum afportata innotuit, cui no. men Maba impofuerunt.

\section{STERCVLIA BaLANGHAS. Linn.}

S. foliis ovatis integerrimis petiolatis, floribus paniculatis $M . S . V$. p. 866 . n. I.

In Tanna infula, e novarum Hebridum congerie, hanc arborem hinc inde in nemoribus reperi, exeunte hyeme florum paniculas et foliorum novam progeniem e gemmis exferentem, fructibus praeteriti anni adhuc in ramulis perfiftentibus Cultis forte ad. numerari debet cum eius nuclei, iuxta Rumphii teftimonium non folum affati eduies fint, et ab Amboinenfibus in hunc ufum adhibeantur; fed et capfulae combuftae pigmentun Ca/Jomba dictum praebeant, cuius frequens eft ufus apud hosce populos.

23. SterCVlia Foetrda. Linn.

S. foliis digitatis. M.S. Y. p. 866 .

Huius cum praecedente eadem eft ratio, et ufus idem. Semel vifa eft, et quidem culta, in 'Tamna infula.

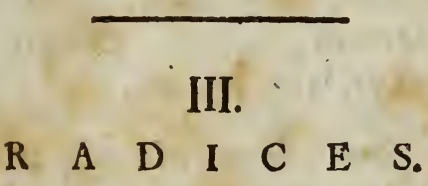

24. CONvolvvlvs chrysorrhizvs. Solandr. C. - - -

D 4

Cosv 
Convolvuli fpecies radice magna, tuberola, farinacea, intenfe fulva, naufeofo-dulcis, in oceani pacifici, infulis intra tropicos fitis non folum, fed etian extra tropicum in Pafchatis infula (Oftereiland) et in Novae Zeelandiae regionibus borealioribus paffim inter plantas cultas reperitur. Hanc pro varietate Convolvuli Batatae habui, b. Solander autem qui etiam herbam et florefcentian vidit, ad novam lpeciem fetulit, cui nomen Convolvuli chryforrhizi impofuit, tefte Parkinfonio (Journal. p. 37.). Quod fi cum Rumphio credimus Convolvulum Batatam Linnaei ante adventum Hifpanorum ex America meridionali, in Philippinis et Moluccanis infulis prorfus ignotum incognitumque fuife; inde novo argumento Illuftris Solandri fententiam confirmari intelligimus. C. Batatas enim apud incolas infularum Amboina, Banda, Ternate, Baly, cognomine adiecto Caftcla diflinguitur, quo eundem ab hifpanis (cantilianis) acceptum indigitant. Taheitenfibus autem et reliquis oceani aulftralis gentibus illa fpecies, quae harum infularum propria videtur, Umara audit, vel cum adfpiratione $G_{b b}$. marra aut Gumalla.

25. DIOSCOREA ALATA. Linn.

D. foliis cordatis (oppofitis) caule alato bulbifero. $M$. S. $V$. p. 888. n.

Ubi vulgare, digitatum, anguirum, anniverfarium, ovale. Rumph. amboin. V. t. 120. 12 I. '122. 123. 125.

Synonyma onnia heic enumerata utique referri debent ad D. alatam, cui nomen fativae ineliori iure competit, quam illae fpeciei foliis alternis, quam $b$. Linneus, nefcio qua inductus ratione fativam denomi- 
minavit. Haec enim D. alata Linnei tan in India orientali, quam occidentali, nec non in Africa aequinoctial 1 et etiam paffim in oceani auftralis infulis intra Zonam torridam, immo usque ad Novam Zee: landiam, $a b$ incolis colitur ob fapidiffimas faluberrimasque radices, quae toltae aut fimpliciter coctae paa nis loco adhiberi poffunt.

Ubi vulgare Rumphii (t. I20.) quod Linneus inter fynonyma D. oppofitifoliae retulit, certo ceititus ad D. alatam pertinet, et enim folia cordata et caulem alatum et bulbos in caule ( p. 347.) gerit.

Radix facpe tripedalis eft, et triginta librarum ponderis, craflitie femoris, cortice nigro, carne alba feu purpurafcente, vilcida, poft coctionem farinacea. Succus radicum recens acris eft, er in cute pruritum excitat. Nucleus Cocos rafpatus cum Mufae pulpa et Dioforeae radice commixtus, frixusque in formam pultis, 'Taheitenfibus in deliciis habetur. Varietas. radicibus fuldigitatis, Rumph. t. I2I. frequens occurrit in Amicorum infulis, ubi etiam anguinam iftam Rumph, t. I22. vidimus, et aliam, cuius radices mi-? nufculae pondus unius librae vix fuperabant, cortice cinereo-albido (Cook. it. novif. l. c.). In omnibus hisce infulis malaico vocabulo Ufi five Ubi no. tiffima eft.

\section{ARUM ESCULENTUM. Linn.}

A acaule, foliis peltatis ovatis integerrimis: bafi emarginatis, M.S. $V$. p. 827. n. 7 .

Indigenae infularum anfralium in huius radicis opet of a cultura magnos labores fubeunt; gaudet enim folo inundato primis menfibus, deinde in ficco D 5 col. 
collocanda eft, ope foffae circa campos ductae. Radix niragna, tuberofa, nutrimentum commune horum hominum, acerrima eft, crudaque oris pruritum et excoriationem caufatur; in cinere autem fervido toIta, acrem hanc qualitatem amittit, fitque blandior et fapida; gravat tamen ftomachum debiliorem, alvumque conftipat. Folia difci vel orbis loco, quo cibi imponendi funt, in India ufurpantur, funtque fuperne glauca et inftar ferici tomento imperceptibili molliflima. Javanice haec fpecies vocatur Tallas, talieitenfibus et novae Zeelandiae incolis Tallo five Tarro. Reperitur pafim in omnibus infulis oceani aultralis, intra tropicos, exceptis defertis et demerfis; colitur etiam in nouae Zeelandiae extremitate boreali. Kelady fativun Rumph, herb, amb, tom. V. p. 313. t. 109. ad hanc fpeciem potius quam ad $A$. Colocafiam pertinere videtur.

\section{ARUM MACRORHIZON Linn.}

A. acaule, foliis peltatis cordatis repandis: bafi bipartitis. $M . S . V$. p. $827^{\circ}$ n. 8 .

\section{Arum fativum Rumph amb. V. t. 106.}

Colitur paffim cum praecedente. Radicem feu potius fipitem habet maximum, brachii craflitie et Iongitudine, quo elixo et a volatili acredine libera. to indigenae vefcuntur. Folia maxima amplifima, utrinque nitida, glabra, laete virentia. Fructificatio a charaftere generico aliquanto recedit, flofculis in fpadice omnibus et fingulis hermaphroditis.

cor, nulla, 
stam. Filamenta nulla. Antberae fex, fpadici adnatae, didymae, fingulos flylos cingunt.

PIST. Girmen fubrotundum. Styhus folitarius, brevis, craflufculus; apice depreffus. Stigma, macula orbiculata in apice ftyli.

SER. $\{-\cdots$

Taheitenfibus vocatur Apè; ceylanenfibus $H_{q} b$ b. $r a$; incolis infularum Amicorum et Sandvigiarum Kappe.

28. tacca pinnatifida. F. $M . S . V \cdot$ p. 455. n. $I$.

Tacca fativa, et fylvatica. Rumph. amb. tom. V. tab. II2. II 4 .

Radix tubsrofa, tuberibus pluribus congeftis, fibrillas hinc inde emittentibus.

Folium radicale fubfolitarium, petiolatum, ternatum biternatumve, foliolis laciniato-pinnatifidis, acutis, laevibus, patentibus ad latera petiolorum fubdecurrentibus, dodrantalibus pedalibulve. Petiolus teres, fifulofus, fulcatus, (in varietate domeftica laevis, maculis fordidis variegatus) bafi infuna fcapum vaginans, patens, laevis.

Scapus femiorgyalis, herbaceus, fiftulofus, verfus apicem lulcatus, erectus. Vmbella terminalis feffilis fimplicifima. Inuolucrum / circiter heptaphylJum, foliolis bipollicaribus, duobus exterioribus feffilibus, pinnatifidis, caeteris fpatulatis laevibus, lanina fubrotunda, apice acumine breviffumo. Peduncu- 
li quatuor ad octo vfque, fere longitudine involucri, fumplicifimu, fubangulati vniflori, patentes. Fila octo feu duodecim longiflima involucro pluries longiora patentia, exta umbellam dependentia, intorta, pedunculis interjecta, bractearum loco adfunt.

CAL. Perianthium fuperum, hexaphillum, perfiftens, foliolis ovatis, acutis, erecto-conniventibus receptaculo infertis, tribus interioribus latioribus.

cor. Petala fex aequalia, calyce tecta, eoque dimidio breuiora, fornicata, medio fell collo angtAtiora.

sтам. Filamenta duodecim brevifima feu vix ulla, petalorum cucullis, per paria inferta. Antherae oblongae, retrorfum arcuatae, unifulcae in medio dorfi parieti fornicis petalorum per paria affixae, et ita arcte approximatae ut binae unicam referant.

PIST. Germina tria conniventia? vel faltim unum trilobum exigum, Styli tres breviffimi. Stigmata obcordata biloba.

PER. Bacca ficca, nigra, ovata, rugofa, obfolete angulata, calyce coronata, trilocularis polyfperina, diffepimentis exficcatis: immatura hexangularis, carnofa, diametro bipollicari.

SEM. plurima, ovata, compreffa, ftriata, brunnea, pulpa exficcata cohaerentia.

Radix Taccae cruda inter amariffimas acerrimafque jure habetur, tametfi cultura hanc proprietatem aliquanto mitigavit. Rafura radicis crudae, aqua fubigitur, quae continuo abiecta et lotione reiterata, farina tandem in fundo vafis dejicitur candidiflima, amylo funillima, iterum bis terve abluenda, donec in 


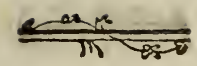

aqua nulla deguftari poffiit acrimonia, Farina ad folem exficcatur. Prima lixivia five infufa follicite abjiciuntur, cum e radice noxias, immo lethiferas adeo qualitates in fe fufceperint. in Taheiti adjacentibusque Societatis infulis ex hac farina placentam gelatino. fam praeparant, fapidam, et inftar Salep, quod ex Orchide Morione (nec non O. militari et malcula) paratur, bene nutrientem. In Banda, moluccani archipelagi infula ubi panis e medulla Sagueri arboris factus non abundat, farinam 'Taccae in plagulis lapideis prius calefactis compingunt, pinfuntque placentam five panem quadratum ipfo Sagu meliorem. Vfus medicus huius radices apud eosdem homines viget, qui eandem emplaftri forma vulneribus profundis, telo vel tribulo inflictis imponunt. Sylveftris varietas Taccae, phalli fpeciem parafiticam e radice prodeuntem fultinet, a Rumphio delineatam, nobis autem non vifam. Varietas fativa taleitenfibus $P i a$, fylveltris $e-V e^{\prime}$ dicitur.

\section{DRACONTIUM POLYPhyllum. Linn.}

D. fcapo breviffimo, petiolo radicato lacero, foliolis tripartitis, laciniis pinnatifidis. $M$. S. $V$. p. 829. n.

Colitur in locis umbraticis nemorofis infularum Societatis; taheitenfibus Tetweh dictum; quod tamen nimis nomini $T$ accae filveftris confonum effe videtur.

Radix acris, ficut omnes huius ordinis (piperita. rum); ab incolis comeditur, deficiente artocarpi annona. An iisdern quoque vires huius radicis medicae, quibus Japonenfes, tefte Thunbergio (Fl. Jap. p. 234.) abutuntur, innotuerunt? Gravis quidem, fed vix injuriofa fufpicio, fi ad milites iffarum infularum Errioy dictos, refpicimus, qui etiam recens enixos par- 
tusamicarum ingulant, vt barbarae legi fatisfaciant, de non fulcipiendis, liberis.

30. DGIDGI, radix. (Jeejee)

31. MAWHAHA, radix.

Hae radices reperiuntur in amicorum infulis, atque cultura conveniunt cum Mula et Aro. Mawhaha fapore radicibus folani tuberof fimilis effe dicitur. Mentionem harum primus injecit Cook in novis, itin. Vol. I. p. 332. 393.

\section{DRACAENa terminalis. Linn.}

D. herbacea, caulefcens, foliis lanceolatis. M. S. $V$. p. 334. n. 4.

Radix cylindrica, praemorfa, brevis, fibrillas raras emitit. Caulis trutefcenti-herbaceus, teres, ereclus, e cicatricibus foliorum emortuorum quafi fqua matus, fere orgyalis, faepe ramofus, ramis erecto patentibus, adfcendentibusque, faepe etiam nullus vel breviffinus, apice foliofus.

Folia petiolata, terminalia, conferta, ovato-lanceolata, acuta, acuminata, integerrima, laevia, multiplinervia erecta, glabra, bi feu tripedalia; petioli pe. dales five bipedales pollicem craffi, erecti, canaliculati, equitanti - imbricati, caudicis apicem veftientes.

Pedunculus femiorgyalis teres, laevis, erectifculus, craflitie digiti. Racemus decompofitus, fpicatus, foliatus. P'edunculus vniverfalis erecto- patens teres, laevis, fulcatus; partiales alterni, teretes, laeves, fulcati, patentifimi, pedales et ultra, partialiores ejusdem fitus et figurae fupremi fenfim minores, omnes fpicati. Flores fparfi, feffiles, confertiuiculi, albi aut * in varictate $\beta$ purpurei, femipollicares, Stipulae? foliis ex- 


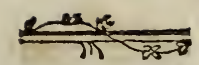

frnilimae, oblongo lanceolatae, fffiles, integerrimae ex ins ad bafin pedunculorum folitariae, inferiores magis acuminatae. Bracteac tres fubrotundae albidohy:linae, concavae, quarum extima major, floris bafin veltiunt calycis loco.

\section{CAL. nullus.}

cor. Monopetala, bafi cylindrica, profunde fexpartita, laciniis oblongis, obtuft, revolutis.

sтaм. Filamenta fex fubulata, petali laciniis fe. re breviora. Antherae fagittatae, bafi bipartitae.

PIST. Germen fuperum, conico - ovatum, glabrum, apice peris tribus perforatums. Stylus fubtrigonus corolla paullo brevior. Stigma trigonum limplex.

PER. Bacca irrgulariter globofa, trilocularis po. lyfperma, nigra.

SEM. aliquot, arillo pulpofo involuta, vt quafi vnum videantur, in quovis loculamento.

Varietas $\beta$ purpurea foliorum venas, petiolos, pedunculos et flores purpureos habet. Terminalis domeftica alba et purpurea, nec non angufifolia Rumph. Amb. IV. p. 79.81.tab. 34.35. omnes hunc fpectant. Idem celeberrimus auctor radicem huius racaenae contra Diarrhaeas et Dyfenteriam praeftantiffimam laudat, quum vires potius in edulcorando et obtundendo quam in conftringendo exferat. Incolis infulae o- Taleiti cibum praebet. Folia apud incolas infulae Ternate $\mathrm{Nga} / \mathrm{fi}, \mathrm{i}$. e. mendacia vocantur, quia binos colores, viridem nempe et purpureum exhibent; eadem fi alicui mittuntur, illum pro mendaci declarant. Apud indigenas autem infularum in oceano pacifico huius plantae folia pafiim amicitiae et pacis fig. na ac pignora funt. Diis ibidem facra habetur, et 
64

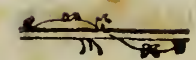

inprimis ad coemeteria et aras colitur. Taheitice $T$, five Tibi i. e anima.

\section{IV. \\ O. L E R A.}

\section{DRACAENA InDIVISA. F.}

D. arborea, foliis enfiformibus auktis, ra. cemo (laterali?) compofito. F.

Haecce arbor, cum proxime fequentibus, Areca oleracea et fapida, Apio graveolente, Tetrago: nia halimifolia, Lepidio oleraceo et pifcidio, atque Soncho oleraceo inter praeftantifimas plantas efculentas in terris aufrafiae merito recenferi debet; licet eaedem vix ab incolis et indigenis vfurpentur; fed Europaeis, maxime polt longinquum iter insritinum Scorbuto laborantibus, faluberrima olera praebeant.

Haec Dracaenac fpecies nafcitur in fylvis ad portum Novae-Zeelandiae, autralioris, cui nomen obfcuri (Dufkybay) Cookius dedit, in fcopulis mari faepe proximis. Ejus baccae ni fallor ab incolis comeduntur: tolia autem tenella convoluta, feu potius hybernaculum arboris ex apice trunci prodiens, pedale, inter folia reconditum, albo flavefcens, blandum, medullofum, cum oleo et aceto inter optima acetaria jure habetur. Baccae menfe maio five hyeme ineunte maturefcunt. In temperatioribus Novae Zeelandiae regionibus circa aeftuarium Reginae Charlottae, aliera Dracsenae fpecies reperitur, quam heic practcrmitto, eum eius in re cibaria vfits nobis nor innotuerit.

Cau- 


\section{$\frac{e^{a n}}{m-\sqrt{2-y}}$}

Caulis arboreus, teres, rimulofus, fimpliciflumus, indivilus, virens verfus apicem foliis veftitus, bi leu tri-orgyalis.

Folia terminalia feffilia, femiamplexicaulia, bafi imbricata, late enliformia, membranacea, acuta, integerrima, patentia, longidinaliter ftciata, laete virentia bipedalia, painum lata.

Racemus cnmpofitus, lateralis ex alis foliorum (fel forlan folia jan feriora, feu fecundi anni, prodierant), ovatus, nutans, racemis partialibus in formam cylindricam thyrfoideam digeftis. Pedunculus univerfalis bi-feu tripedalis, teres, laevis, herbaceus, diametrolfefquipollicari: partiales fpithnmei approxinati, erecto-patentes, teretes, laeves, bafi inftructi foliolo lanceolato, pedunculi longitudine; undique fparfim e pedunculo univerfali prodeuntes. Pedicelli uniflo. ri, breviflimi, horizontales. Bracteae ad bafin pedicelli duae, minimae, lanceolatae, acutas, concavae.

car. nullus.

cor. Petala fex oblonga, fubreflexa, aequalia, bafi cohaerentia.

sтам. Filumenta fex, fubulata, fere longitudine peralorum, eorumque bafi inferta. Antberae oblongae, incumberites.

PIsT. Germen fuperum. Stylus filiformis breuis. Stigma.

PFr. Bacca globofa, caerulea, fupra pundtis tribus excavatis notata, flylo perfiftente mucronata, trilocularis, polifperma. 
SEM. in fingulo loculamento circiter feptem, arillo feu membranila involuta, ut unicum crederes, atra, glabra, femilunaria, triquetra.

OBs. Character genericus Dracaenae in hasce duas fpecies, D. teminalem Linn et $\mathcal{O}$. indivifam noftram non perfecte quadrat, quun harum baccae plane polyfpermae fint, quastamen trifpermas character genericus iuxta novflimam Syftematis L.inneani Editionem XIVtam p. 31\%.3,3 requirit Forte haec nota D Draconi foli competit; vel etiam pro unico fenine habebatur arillus feninibus farctus, Anne effentialis differentia inter Alparagi, Dracaenaeque genera in hocce arillo confiftit?

\section{ARECA OLER ACEA. Linn.}

A. foliolis integerrimis M.S.V. p. 986.n.2.

Hanc arborem femel vidimus in hortis infulae Tanune, fed tum temporis neque florentem, neque fritus profrentem. Veri tamen fimillinum eft, eandem propter fructuum ad rem cibarian ufum ab in olis cultam fuife. Eius gemma ficut praecedentis Dracaenae et omniun p.lmarum, edulis eft, dulcis te delicatula, tanquam br fice caules teneriores, aut ynarae receptaculum. Ob def.ctum florefcentiae eandem ulterius exam nare non potuimus; ad hanc fpeciem amandandam elle, ex Cel. Iacquini defcriptione conclufimus.

\section{ARECA SAPIDA. Solinder.}

\section{A. - - -}

Reperitur fpontanea in nova Zceiandia usque ad aefuarium Charlottae reginae et frequens in Norfolciae infula deferta. Huius praecipue Cor five Caput 


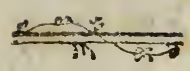

in deliciis eft apud nattas Europaeos, et cum oleo et aceto parari folet. Nomen a b. Solandro mutuati fumus, cum neque frictum neque florefcentiam buius paimae examini nohro fubiicere nobis datum effet. Huilus forte generis êf Niu-gula, (Cocos rubra), Palma, cuius Cookstus meminit in Tonga infula, itineris 130 vifimi tomo I. p. 332 .

36. APIUM GRATEOLENS. Linn.

A foliis caulinis cuneiformibus. M. S. $V$. P. 292.

Abundat in novae Zeelandiae littorihus; legitur etiam in Pafchatis infula, nec non intra tropicos in infulis demerfis, fponte proreniens, incolis quantum fcio, inulitatum, nautis vero fcorbuticis gratiflunum et maxime falutare.

\section{TETRAGONIA HALIMIEOLIA. F.}

T. herbacea, papulofa, foliis ellipticorhombeis petiolaris, pedunculis axillaribus uniforis fubrolitariis, fruetu cornuto. $\mathrm{F}$.

Habitat in Nova Zeelandia ad oras fylvarum in plagis fenticofis et arenofis, nec non intra tropicos in littore infulae Tongatabio. Incolis intifitata, fed in. ter olera praeftantilina collocanda, Influ enin im. mortalis Cookii dum in portu moraremur, quotidie pro ientaculo et prandio cocta nantis apponebatur. Tota planta confperfa eft pundtis minutiflinis cryitallinis, quales in Atriplice, Chenopodiis, Mefembryanthemisque nonnullis obfervantur, tunde papulofa vel etiam rorida alici poffet. Deferiptionem in folo natali confcriptam non prorfus fupervacanean fore 
arbitror, licet hanc noftram cum $T$ expanfa M. S. V. p- 467. n. 6. pro eadem fpecie declarare vix dubitem.

Caulis herbaceus, laevis, procumbens, ramofus, ftriis elevatis e marginibus petiolorum decurrentibus fubangulatus, penna anferina parum craffior, debilis. Rami plures elongati, teretes, patentes.

Folia alterna fubpetiolata, ovato - rhombea, obtufiufcula, integerrima, horizontalia, internodiis breviora, fefqui-pollicaria. Petioli tenues fupra planiufculi, pollicares.

Pedunculi fubfolitarii axillares uniflori breviffmi. Flores flavi.

CAL. Periantbium quadri - rarius quinque partitum, laciniis fubaequalibus ovatis, fubacutis, intus coloratis, una reliquis latiore magis rotundata.

cor. nulla.

stam. Filamenta fedecim vel duodecim fubulato - capillaria, calyce breviora. Antberat fubrotundae didymae, erecto incumbentes.

pist. Germen minimum. Styli fex, rarius quinque, filiformes, decidui, fubreflexi, longitudine ftaminum. Stigmata fimplicia.

PER. Drupa rudis, turbinata, five obverfe conica, carnofa, verfus apicem tetragona five pentagona, angulis productioribus acutis cornuta.

SEм. Nux offea, loculamentis numero ftylorum refpondentibus monofpermis. Nuclei folitarii, ovati, albi. 


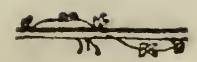

38. LEPIDIUM OLFRACEUM. F.

L. foliis|elliptico-oblongis acutis ferratis, floribus tetrandris. F.

Habitat in Novae Zeelandiae littori arenofor inprimis ad aeftuarium Charlottae, locis dumofis fubumbraticis. Cum Apio et Tetragonia halimifolia quotidianum olus nautarum erat, dum in hoc portu commorati fumus. Inter alimenta antifcor. butica nunquam fatis laudandum, faporis blandi, paullulum acris, ad fpinachiae vel etiam ląucae faporem accedentis, paullo flatulentum, alvum modice aperiens.

Caulis perennis, herbaceus, teres, laevis, ereeto-adfcendens, ramofus, ramis paniculatis, a pedali faepe in femorgyalem altitudinem excrefcens.

Folia fparfa, alterna, elliptico-oblonga, utrinque attenuata, profunde ferrata, patentia, glabra, palmaria ; fuperiora minora, apice tantum ferrata. Petioli (fi hoc nomine malis vocare folii partem inferiorem anguftiorem) foliis dimidio brevioris, plani extrorfum carinati, caulem excipientes.

Pedunculi univerfales terminales, teretes, laeves, aphylli; Racemi fimplices, fub inflorelcentia coaretati, corymbofi, fructiferi palmares, cylindrici. Pedicelli plurimi, fparfi, filiformes, teretcs, patentes, femipollicares, uniflori. Flores albi, bilineares.

CaL. Perianthium tetraphyllum deciduum, foliolis fubrotundis concavis, patuli, extu fubpubefcentibus.

cor. Petala quatuor fubrotunda integra, concava, calyce duplo maiora, ungue lineari lamina dimidio breviore. 
stam. Filamenta quatuor, aequalia, fubuata erecta, longitudine fere corollae. Antherae fubglobofae flavae.

pIsT. Ge men ovatum. Stylus cylindricus brevifi. mus, perfiftens. stigna obtufun.

PËr. silicula ovato - cordata, compreffa, bilocularis, bivalvis, valvulis navieularibus, monofpermis, diffepimento lanceolato.

sqm. folitaria, ovata, acuta, flavorubentia.

39. IETIDIU Prscidium. F.

L. foliis elliptico-oblongis, àcutis integerrimis: floribus tetradynamis $F$.

Habitat intra tropicos in infulis demerfrs, etiam in Fulaeine et in Botanices infula ad novam Caledoniam adjacente. Incolis ufui venit ad pifces inebriand s et capiendas; nobis tamen inter acetaria apponi folebat, acerrimumm. Simile praecedenti, fed multis notis effentialiter diftinctum.

Caulis herbaceus bipedalis, ramis patenti adfcendentibus, teretibus, laevibus.

Foliaalterna, elliptico-oblonga, acuta, integerrima, patentia, laxa, bipollicaria, inferiora caulis bafi attenuata, elongata fere petiolata.

Racemi terminales, folitarii, fimplices. Pedunculus univerfalis teres, hevis, erectiufculus, binalmaris. Pedicelli fparfi, filiformes, patentes, corymbofi, laeves, uniflori, bilineares. Flores parvi.

CAL. Periantsinm tetraphyllum, foliolis concavis, ovalibus, ereAtufculis, intus albicantibus. 


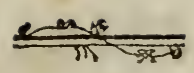

\section{8}

COR. Petala, quatuor aequalia, alba, fpatulata, calyce longiora, anguftiora, cum eius foliolis altermantia.

Nectarium e glandulis fex minutis compreffis viridibus, ftaminibus interjectis.

sram. Filamenta fex fubulata longitudine calycis, horum duo, carinis germinis opopofita paullo minora. Aistberue minutae.

pisr. Gemnen oblongum, compreffum, utrinque carinatum. Stylus cylindricus breviffimus. Stigma fimplex excavatum.

PER. Silicula ovalis, compreffa, apice emarginata, bilocularis, valvulis navicularibu's compreffis, carinatis.

SEM. fubfolitaria, ovata, apice attenuata, pedicello minimo valvularum apici adfixa.

40. Sonchus oleraceus. Linn.

$S$. pedunculis tomentofis, calycibus glabris. M.S. V. p. 712. n 5 .

Reperitur in Nova Zeelandia et in amicorum in. fulis, fatis frequens. Ejus caules tenelli et folia ju. niora pro acetariis a noftratibus ufurpari folebant. 4I, BOERHAAVIA ERECTA. Linn.

B. Caule erecto glábro, floribus diandris. M. S. V.p. 52 .

Caules plerumque procumbentes et in hac fpecie, ufurpantur ab incolis infularum o - Taheiti et Societatis, fi carior fuerit annona, et oleris loco comeduntur, licet vix aliquid faporis habeant. Planta fylvatica, fponte proveniens. Taheitenfibus Nuna $\cdot$ nun . 


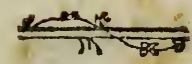

\section{SOLANUM VIRIDE. Solander.}

\section{S. - -}

Huius fpeciei mentionum injecit Parkinfon (Fourn. p. 38). Folia inter olera colta five affata comeduntur. Planta fponte proveniens, apud inco. las vocatur Purabeiti.

43. POkTULACA LUTEA. S.

$$
\text { P. - - }
$$

Herba fimillima $\mathrm{P}$. oleraceae, diftinguenda $\mathrm{ta}^{\mathrm{a}}$ men fi Parkinfonio credas, quinomen a b. Solandro huic fpeciei impofitum, tradidit in Journ. 1- c. Mihi femel, at fine florefcertia in Huaheine occurrit. Crefcit in littore infularum Societatis et demerfarum, quae lithophytorum fabricae incumbunt. Cocta ab incolis oleris loco comeditur, et apud Taheitenfesnomine Aturi diftinguitur.

\section{V. \\ S V C C E D A N E A.}

44. AVICENNIA RESINIFERA. F.

A foliis lato-lanceolatis, fubtus tomentofis. F.

Arbor. Specimina noftra ante florum eruptionem leeta, cum A. refinifera Solandri in herbario Bankfano contuli, et eiusdem fpeciei efie refcivi.

Folia oppofita, petiolata, lanceolata, coriacea, integra, acuta, fuperius nitida, fubtus tomento brevifimo, flavicante incano, bipollicaria. Petioli brevifimi femiteretes, extrorfum rugofi, erectopatentes. 
Pedunculi terminales fubtrifidi, capitulo florum onufti. Gummi ex hac arbore exfudans forte idern eft, quo barbari novae Zeelandiae homines vefcuntur, ut patete diario navarchi gallici Crozet, p. 67 .

"Je leur ai vu manger une efpèce de gomme „de couleur verte, dont ils paroiffent faire grand „cas. Je n'ai pu favoir, de quel arbre ils la tiennent. "Quelquesuns de nous en ont mangé, en la faifant "fondre dans la bouche; nous l'avons tous égale"ment trouvée d'une qualité très-échauffante."

\section{HiBISCVS TILIACEVS. Linn.}

$\mathrm{H}$. foliis cordatis fubrotundis indivifis acuminatis crenatis, caule arboreo, calyce exteriore decemdentato $M . S, V$. p. 629. n. II.

Calycis nota ad dignofcendam hanc fpeciem praeftantiffima eft. Folia enim variant, aut fimpliciter cordatafere orbiculata; aut in tres, quinosve angulos acutos excurrentia; pubefcentia vel nuda; profunde crenata vel integerrima; majora, vel minufcula. Flores fulphurei, ampli, bafi faturate purpurei, petalis fubrotundis, unguibus ob. longis.

Reperitur paffim intra tropicos in littore infularum Societatis, Marchionis, Amicorum, novarum Hebridum et novae Caledoniae. Cum artocarpi meffis deficiat, Taheitenfes huius Hibifci corticem exfugunt : novae Caledoniae autem homines faepius hoc alimento infulfo ac minime nutriente vefcebantur.

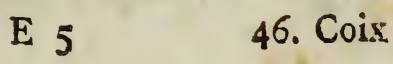


46. CoIX Lacryma. Linn. M. S. V. p. 842.

Semina huius graminis dulcia funt et edulia. Re: perta a nobis eft in Tongatabu et $\mathbf{E}$ - uwa, Amicorun infulis: netcio an cultis ibidem adnumeretur.

47. pteris esculenta. F.

P. frondibus fupradecompofitis fulcatis, foliolis pinnatis, pinnis linearibus decurrentibus, fummis brevioribus. F.

Reperitur in fylvis infularum Societatis. Radices ab incolis inopibus et famelicis exfuguntur, infipsdae, parum nutrientes lignolo - fibrolae.

Frondes fupradecompofitae, triplicato-pinnatac, maximae, radicales glabrae, Ripite fuperne fulco. exarato, divifuris ounnibus alternis, univerfalionbus interdum oppofitis.

Foliola pinnata, circiter bipollicaria, pinnis line aribus integerrimis obtufis, morgine revolutis, coriaceis, approximatis, decurrentibus, inferioribus discretis, hinc inde dentatis, feu pinnatifidis, extimis fenfim brevioribus.

Fructificationis lineae marginales fere totum discum occupant, membranula tenui femina vix obtegente.

Taheitenfibus $e \cdot$ Narrd.

48. POLYYOD UM MEdULlare. F.

P. frondibus bipinnatis: foliolis pinnatis acuminatiffimis: pinnis oblongis fubfalcatis acutis, crenatis, ftipite afpero, caudice arboreo. F.

Hace filicis fpecies in fylvis Novae Zeelandiae treguens eft, et apud incolas Mamagu dicitur; hi radicem 


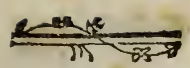

dicem et caudicis inferioris medullam toftam comedunt; huius enim fubftantiae mollis et pulpofae fapor quandam fimilitudinem cum rapae fapore habet, et quidem huic pracftat, ita ut ad medullam Saguari arboris accedat. In medullari fubftantia huius polypo= dii fuccus glutinofus, rubefcens abundat.

Caudex orgyalis, fpongiofus, fubftantia medullari farclus, extrorfum hifpidus, nigricans, e cafu ftipitum, apice frondibus maximis horizontaliter fere patentibus coronatus. Frons decompofita, orgyalis et ultra, ftipite tuberculis feu punctis callofis exiguis, rubicundis undique afpero. Foliola conferta, pinnata, inferiora bipollicaria, angufta, acuminatifima. Pinnulae omnes feffiles, oblongo-lunatae, acutae, infimae difcretae, crenatae, fuperiores fenfim brevio. res connexae, ut apex folii plane ferratus fit, ferra. turis profundis acutis.

Fructificationes globofae, maiufculae, in difco, fimpii ${ }_{-1}$ ferie.

49. POLYPODIUM DICHOTOMUM.

P. frondibus dichotomis bipinnatis : pinnulis linearibus integris, parallelis. Thunb. $f$. jap.p. 338. t. 37. MT.S. V.p.938. n. 66.

Sponte crefcit in montibus aridis Novae Zeelandiae, nec non intra 'Tropicos, in collibus aridiffimis infularum Societatis. Radice fuper igne torrefacta et lapide vel fulte conquaffata vefcuntur novae Zeelandiae homines, exfugendo parten farinofam, dulces* centem. Defcriptio $\mathrm{Cl}$. Thunbergii, qui eandem plantam in Iaponia legit, optime quadrat. 


\section{$\sqrt{3 x}$ \\ VI. \\ P O T U L E N T A.}

50. PIPFR METHYSTICUM. F.

P. foliis cordatis acuminatis multinerviis: fpicis axillaribus folitariis breviffimis, pedunculatis, patentiffimis. $F$.

Species caute difinguenda a Pipere latifolio quod in Supplem. plantar. p. 91. nefcio quo cafu Piper methylticum vocatur. Etenim non folum notis botanicis plurimis a vero Pipere methyftico, latifolium illud difcrepat, fed etiam toxica qualitate caret, neque in bunc ufum ab incolis unquam adhibetnr, fponreque nafcit per omnes fere infulas oceani auftralis intraltropicos fitas.

Piper methyfticum verum inter plantas cultas earundem infularum paffim reperitur, iis tamen exceptis, quae nigrae gentis fedes funt, novis Hebridibus et Caledonia nova. Inter plantas auten cultas harum regionum non alia maiori cura et follertia, neque tam adfiduis laboribus colitur, quam haec ipfa piperis perniciofiffma fpecies; nam et folum huic culturae idoneum ligonibus crebro fubvertitur, et a herbis fponte nafcentibus liberatur, fimulque calce e coralliis et conchis marinis fatifcentibus, fercoris loco fecundatur. Radix contufa vel potius manducata, et cum faliva humectata, fuccum praebet naufeofo-fervidum, cui affunditur liquor e nucibus Cocos, vel etiam aqua pura. Liquorem fic paratum acrem, natlfeofum, virefcentem harum infularum proceres et facrificuli in deliciis habent; quo minore aquae portione commifcentur pocula, eo pluris exiftimantur, citius enim inebriant et in fomnum refolvunt; nimis frequenter autem repetitum temetuln totum corpus ficco ardore 


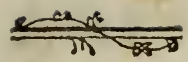

ardore quafi accendit. 'Tum oculi rubere, cutis exarefcere et in fquamulas exfoliari, quae tandem in ulcera leprofa degenerant, vel univerfam corporis maciem tabemque praefagiunt. Sapor huius liquoris omnium maxime ingratus, ipfis perinaciflimis potatoribus ora diftorquet atque membra quatit horore. (Cook in itin. noviff. Vol. 1. p.318). Vires videntur ineffe etiam narcoticas. Nomen apud Taheitenfes: $A v a$, apud incolas infularum Amicorum et Sandvigiarum cum afpiratione dura praefixa: Kava. Caulis plerumque orgyalem altitudinem attingit dichotomus, maculofus. Folia oblongo-cordata, nec ut in P. latifolio fubrotundo - cordata. Spicae rectae breves folitariae, nec aggregatae, longae, nutantes. Perfectam florefcentiam non vidimus.

51. SACCharUM OFFICINARUM, Linn.

S. floribus paniculatis, foliis planis, (lanugine flofculis longiore F.) M.S. V.p. 103 . n. 2 .

Huius graminis magna copia plantatur in campis aridis infulae Pafchatos, cuius incolae ob aquae penuriam, eiusdem culmos dulci fucco plenos exfugunt. In O-Taheiti, Societatis, Marchiorum, Amicorum, Sandvigii infulis minus frequens, cultum tamen nec fponte proveniens, infantibus et pueris relinquitur. 'Taheitenfium $T_{0}$.

52. CONVOLVULUS TURPETHUM. Linn.

C. foliis cordatis, angulacis caule membranaceo quadrangulari, pedunculis multifloris. M. S.V.p. 20 I.n. 22.

Sponte in infulis Societatis, Amicorum, Novarumque Hebridum nafcit. Caules fucco dulcefcente abundant, taheitenfium pueris grato. Apud Parkin. 
fonum (Journ. p. 37.) vocatur Convolvulus alatus; Anne jure, a C. Turpetho leparetur, videant illi quibus lequentem defcriptionem cum vero C. Turpetho Linnaei comparare licebit.

Radix brevis, digiti craflitie, emittens fibras fpithamea longitudine, fibrillis paucis.

Caules tetragoni, membranu'is alati.

Folia cordata, obtufiufcula, interdum angulata, palmaria Petioli lemiteretes, folio dimidio breviores.

Pedunculi teretinfculi, palmares, trifidi, pedicellis fubunifloris. Flores albi, corollis calyce vix duplo longioribus, campanulatis, plicatisque, quinquefidis.

Calycis foliola duo exteriora ovata villofa, reliquis duplo majora, (Hine forte Linnaeus in Flora Zeylanica, p. $3 x$. fingulo flori involucrum diphylJum tribuit,) tria interiora ovata glabra.

Antherae fpirales! Stigma globofo bilobum. Capfula membranacea, globolo - depreffa, bilocularis, loculamentis I. . 2. fpermis. Semina fubrotunia, hinc angulata, atra, obfcura.

Nomen Taheitenfe Taudibau.

53. melaleuca scoparia. F.

M. foliis alternis ovatis acutis fubtrinerviis floribus terminalibus folitariis feffilibus. F.

Melaleuca scoparia M. S. V. p. 699. n. 4. Leptofpermum fcoparium. Forft. Charal. gen. 36 .

Haec arbufcula Novae Zeelandiae vix locum heic meruifet, nifi eius flores et ramuli floriferi recentes, to. 


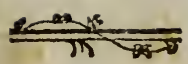

foliis tenellis onuti ab Europaeis Cookium comitantibus in itineribus fuis circa globum terraqueum et ad autralesinfulas, pro infufo, in Theae locum, adhibitae, fuillert. Potus hicce fuaviter aromaticus, tragrans, brevi tamen nimium amarorem contrahebat, fcorbuticis ad inftaurandam valetudinem non nibil forte proderat.

Caulis arboreus, ramofiffinus, erectiufculus, rimofus, cinereus, ramis difruilis, obliquis, fubfaftigiatis, teretibus, aphyllis, fummis virgatis foliolis, apice herbaceis, villofo-fericeis.

Folia alterna fparfa, fubfeffilia, ovato lanceolata, acuta integerrima, trinervia, patentia, plana, laevia, punctata, fupra intenfe viridia, fubtus pallida, bilinearia. Petioli vix ulli, planinfuli.

Flores folitariiterminales, feffiles in apice ramulorum, albi, magnitudine florum ccrafi. Bracteae fub. rocundae, imbricatae, concavae, deciduae calycem ufque ad medium cingentes, obtegentes.

CaL. Periantbium, hemifphaericum, gerininiadnatum, idque umbilicans, margine integerrimo elevato. Limbus e foliolis quinque parvis, ovatis, concavis, cum petalis alternantibus, albis, extus rubicundis, deciduis.

COR. Petala quinque orbiculata, patentiffima, planiufcula, ungue minimo calycis margini interiori inferta, ejus foliolis triplo longiora.

stam. Filamenta vigintiquatuor, ereßta, fubulata, petalis dimidio breviora, calycis margini fimplici ordine inferta. Antherae didymae, fubrotundae.

FIST. Germen hemifphaericum, calyce umbilicatum, inferiusque veftitum, fupra convexiufculum. Stylus filiformis, longitudine et directione ftaminum deciduus. Stzgma capitatum.

PEK, 
PER. Capfula haemifphaerica, calyce umbilicata, fupra planoconvexa, apice puncto excavata, quinque friata, quinquelocularis, quinquevalis, apice debifcens, polyfperma.

nuiffima.

SEM. plurima, minima, linearia, cylindrica, te.

OBS. Haec fpecies a Charactere generico Melaleucae aliquarito recedit, fed tamen eidem generi adnectitur per fpeciem intermediam, nempe M. virgatam.

\section{DACRYdium cupressinem. Solander.}

Pulcherrimum hocce Taxoque affine genus, cuius florefcentiam non vidimus, ab Illuftri Solandro nomen Dacrydii accepit. Reperitur in Nova Zeelandia, vbi Cookius, e junioribus ramufculis, foliis tenellis onutis, et refinofa materia amaricante featentibus, potum, cerevifiae quodammodo fimilem, parari jubebat, cuius praeftantiam in malo fcorbutico difertis verbis extollit in hodoeporico \& fuccedaneum potumcereuifiae e taleis Pini canadenfis confecti, inque America fepten. trionali \& inter nautas notiffimi, vulgo Spruce - beer effe voluit. Non tamen negandum eft, hunc e Dacrydio cupreffino paratum potum, jejunis naufeam et vertiginem nduxiffe, parvo temporis fpatio interjecto tranfeuntem.

Benevole lector, Pauca fphalmata, qux lectim difficilem red. dere poffent fic corrigere velis.

Pag. 8 Lin. 8. pro labis lege labiis. P. 9. 1. 2t. p. craftciuseula 1. craffiuscula. p 15.1.26. p diofcoreaa. 1. diofcoreace p.19. Not, 1. p. in 1. id. p. 20.1 .13 p. granatum 1. Granatum. p. 23.1. 10. p. efibrillis 1 . e fibrillis. p. 28.1 . 21. p. ccrnuntur. l. cernuntur. P. 29. I. 3. p. onginquo 1. longinquo. p 32.1. t. p. geri l. gerit. p. 32. 1.24. p. reigx 1. regia, p. 37.1. 19 p. Arbo 1. Arber. p. 40, 1. 12. p. cuneate 1. cuneatae. p. 4x. p. in habitantium 1. inhabitantium p. 52. 1. 20. p. eollocantur l. collocantır. p. 58.1 .35 p. fingnlis. l. finzulis. $\psi$ 60. 1. 6. p. hexaphillum 1. hexaphyllum. p. 6r. 1 . 1 p. poffit 1. poffit. p. 6i. I. 13. p. radices I. radicis. p. 62. 1. 14. p. emitit l. emitrit. p. 63. 1. a: p. fimilima 1. finillimxe. p. 63.1. 36. p. irrgularite: 1. irregularite:. 


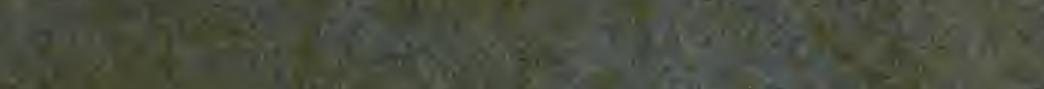

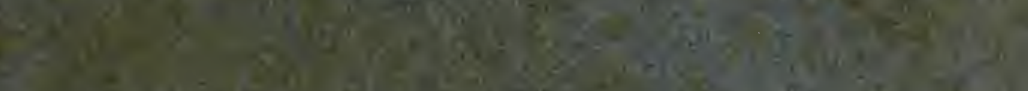
Ix

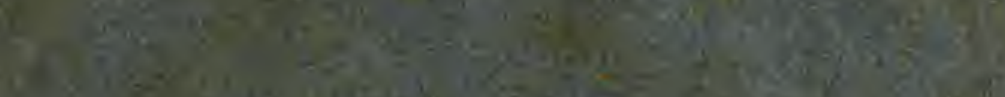

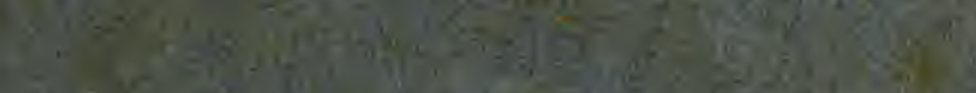

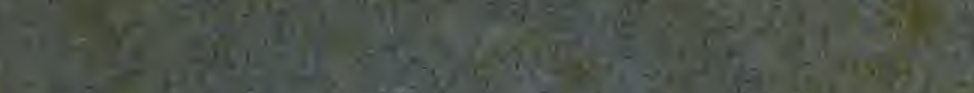

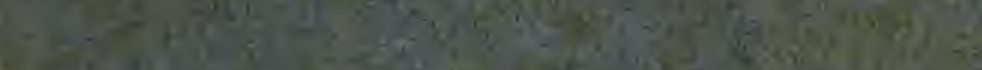

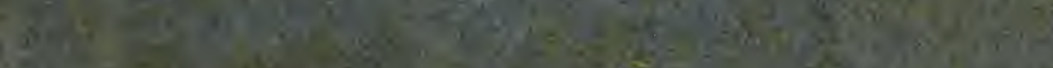

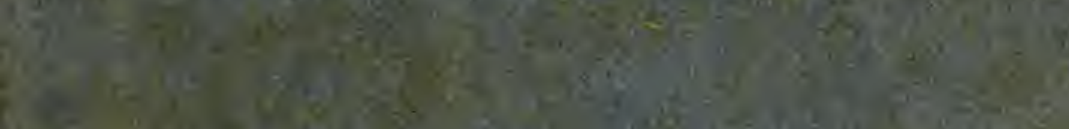
L-

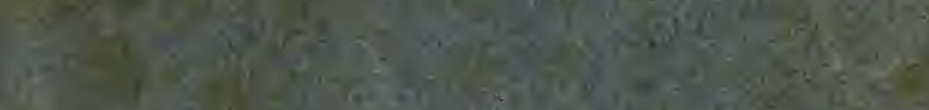

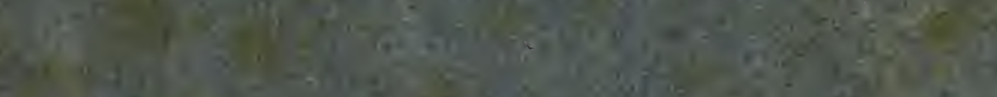

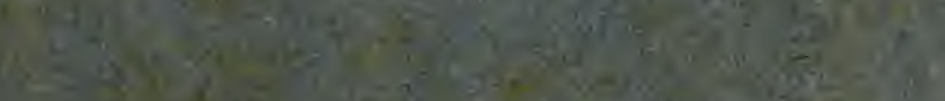

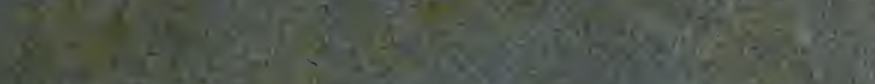

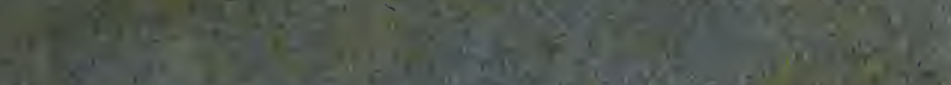

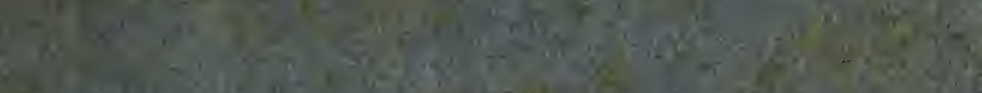
1.

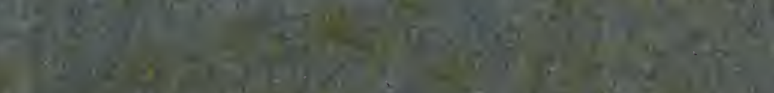

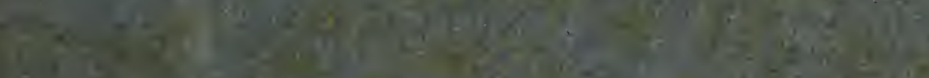

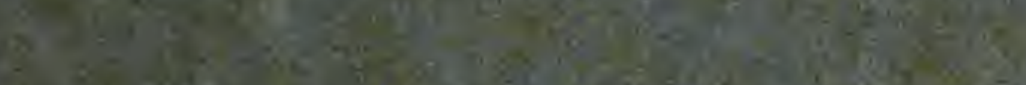

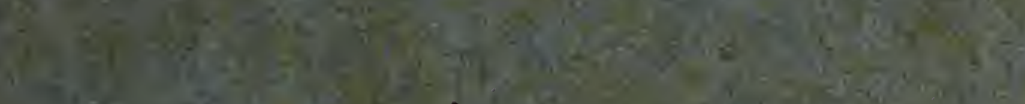

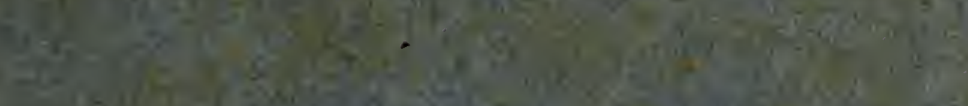

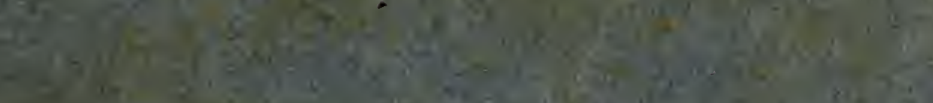

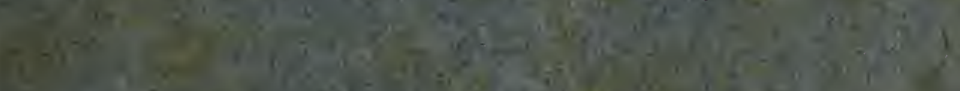

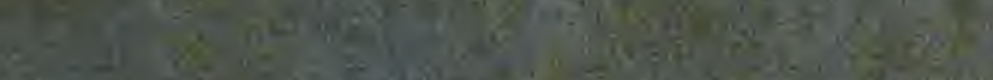

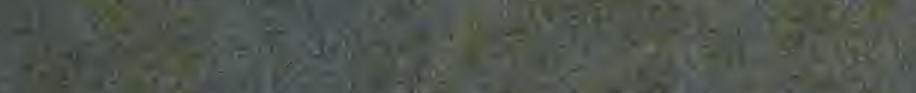

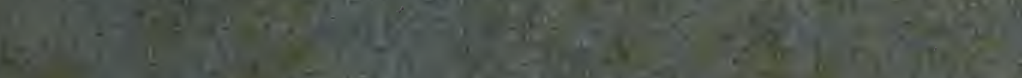

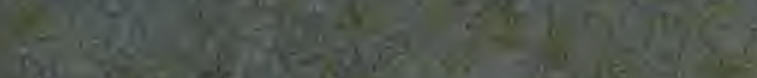

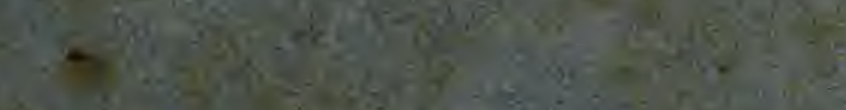

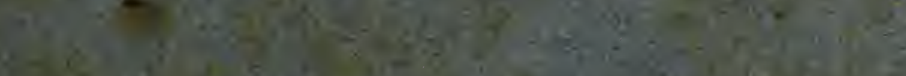

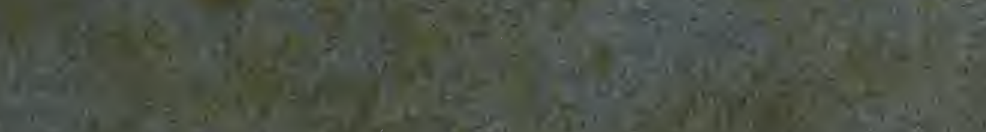

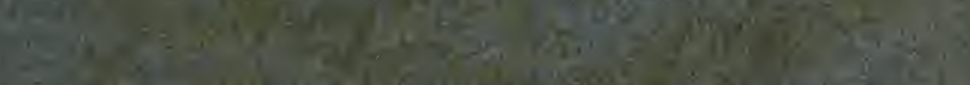

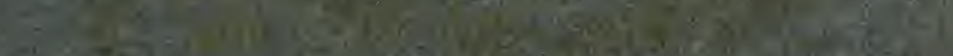

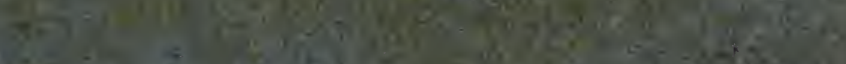

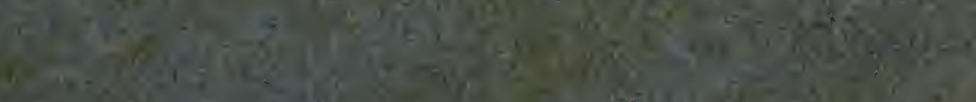

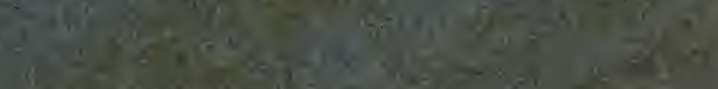




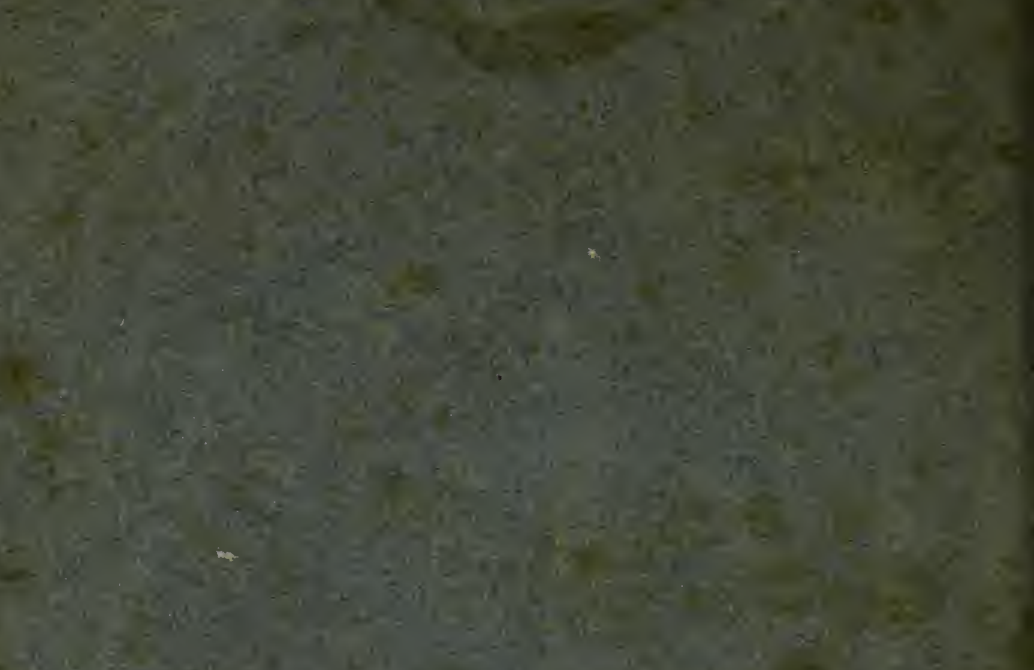

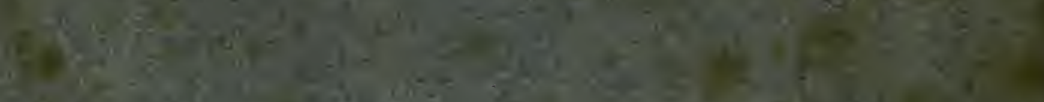

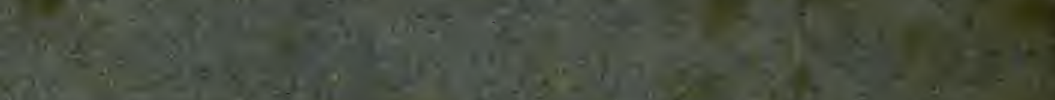

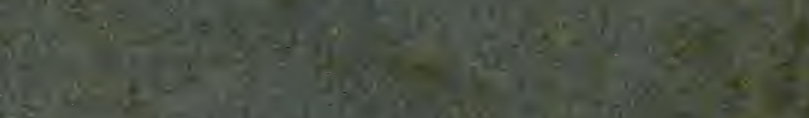

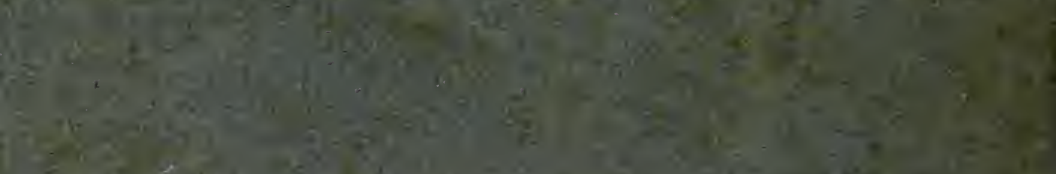

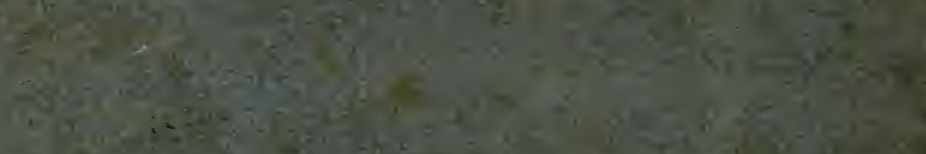

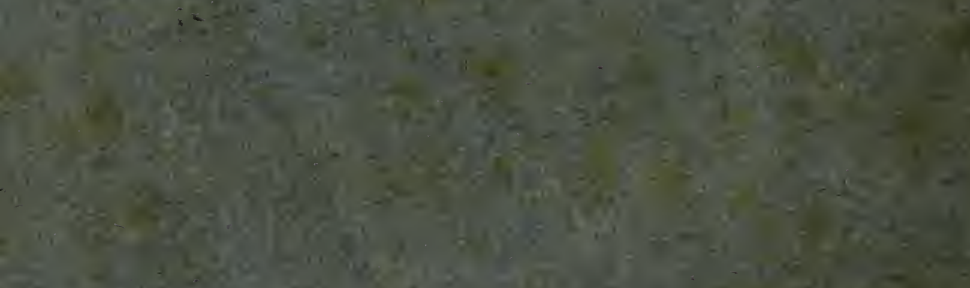

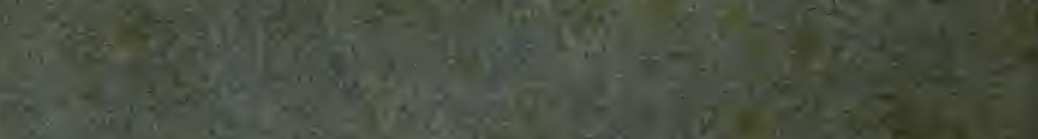

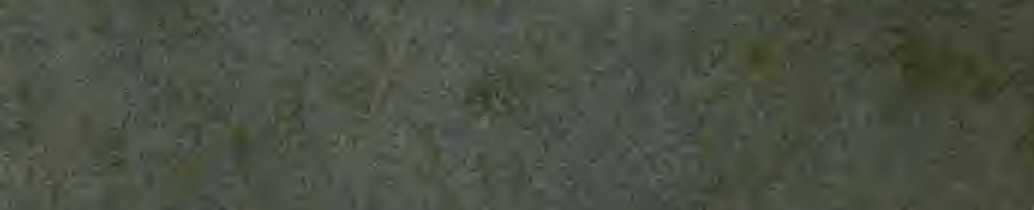

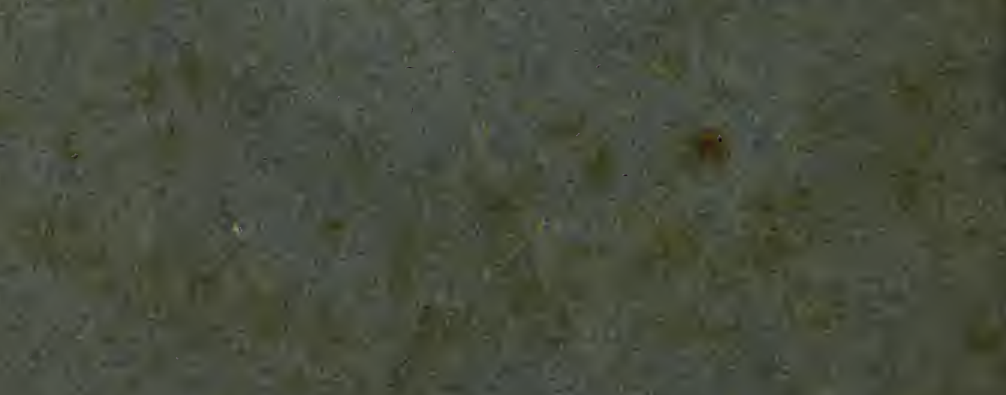

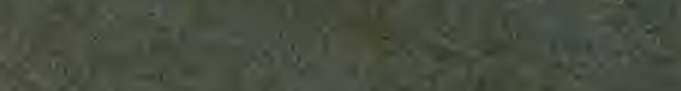


(

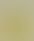

( 

